\title{
Sobre el principio de la injusticia: la exclusión (Octavas Conferencias Aranguren, 1999)
}

\author{
LUIS VILLORO \\ Universidad Nacional Autónoma de México
}

\begin{abstract}
Muchas teorias contemporáneas han intentado fundamentar una teoria de la justicia en alguna forma de consenso, sea fáctico o hipotético. Pero esa vía presenta muchas dificultades teóricas que la vuelven difícilmente aceptable. Un consenso posible podría fundarse en una voluntad ética desprendida de actitudes excluyentes y no a la inversa. Cabe pues explorar una alternativa: dar razón de la idea de justicia por la voluntad de disrupcion de una situación percibida como injusta. Eso es lo que ha acontecido históricamente y, así, la teoría de la justicia se remitiria a esa experiencia de hecho y partiria de su examen crítico. Procedería en dos partes. Primero, la
\end{abstract}

\begin{abstract}
caracterización de la injusticia cuyo principio es la exclusión. Ésta puede definirse como la no-pertenencia a una asociación civil dada, de personas que pertenecen a la comunidad de los hombres. La percepción de la exclusión nos llevaría a determinar tanto los requisitos de pertenencia a una asociación civil como las exigencias planteadas por compartir la condición humana. Segundo, el análisis de las principales formas de exclusión y sus modalidades. De ese análisis podrían deducirse los principios de una teoría de la justicia que partiera del rechazo de una situación de exclusión real, sea o no objeto de consenso.
\end{abstract}

\section{CONDICIONES GENERALES DE LA EXCLUSIÓN}

\section{I}

La generosa invitación del Instituto de Filosofía y de la Residencia de Estudiantes me ha ofrecido una nueva oportunidad de conversar con ustedes sobre temas que nos apasionan. Mi agradecimiento por ello. Mi satisfacción es aún mayor porque estas conferencias se realizan al amparo de José Luis Aranguren. Él concebía la ética con una doble dimensión, personal y social, y dedicó lúcidas páginas a esclarecer la relación entre ambas. Pues bien, en estas pláticas intentaremos abordar un problema ético en el que la moral personal es inseparable de su dimensión social: la justicia. Creo que a Aranguren le hubiera interesado discutir este tema con nosotros.

En las últimas décadas hemos asistido a una efervescencia de reflexiones filosóficas sobre la justicia, su fundamento y sus características; parte, tal vez, de un interés renovado por la ética política. 
La mayoría de las reflexiones comparten un punto de vista: el de sociedades desarrolladas, las que han superado ya, tanto umbrales insoportables de injusticia económica y social, como sistemas de dominación tiránica. En estas sociedades, sobre todo después de la Segunda Guerra Mundial, ha sido común la instauración de regímenes políticos basados en un consenso entre ciudadanos con derechos iguales. El filósofo, al inclinarse sobre temas de la sociedad humana, no puede menos de reflejar el ambiente histórico al que pertenece. Por eso las teorías más en boga para fundamentar la justicia, suelen partir de la idea de un consenso hipotético entre sujetos iguales, que se relacionan entre sí en términos que reproducen los rasgos de una democracia bien ordenada.

Pero, para bien o para mal, hay quienes tenemos que reflexionar sobre los mismos problemas en medios muy diferentes: sociedades donde aún no se finca la democracia, donde reina una desigualdad inconcebible para unos países desarrollados, donde el índice de los expulsados de los beneficios sociales y políticos de la asociación a la que teóricamente pertenecen es elevado. Nuestro punto de vista no puede ser el mismo. En nuestra realidad social no son comunes comportamientos consensuados que tengan por norma principios de justicia incluyentes de todos los sujetos; se hace patente su ausencia. Lo que más nos impacta, al contemplar la realidad a la mano, es la marginalidad y la injusticia. Si queremos partir de nuestro conocimiento personal del mundo en torno -punto de partida, en mi opinión de toda reflexión ética auténticano podemos menos que considerar desde una perspectiva distinta los mismos problemas que ocupan a los filósofos de países occidentales desarrollados. Podriamos entonces ensayar una vía de reflexión igualmente válida. En lugar de partir del consenso para fundar la justicia, partir de su ausencia; en vez de pasar de la determinación de principios universales de justicia a su realización en una sociedad especifica, partir de la percepción de la injusticia real para proyectar lo que podría idealmente remediarla. Para ello tendríamos que precisar cuál es el principio de la injusticia, entendiendo por "principio" la explicación última de las distintas formas en que la injusticia puede presentarse, su condición necesaria, supuesta en todas sus variantes. Se trataría entonces de determinar las características de una relación de justicia posible a partir de ese principio de injusticia, y no a la inversa.

Una aclaración: no pretendo llegar, por esta vía, a una teoría de la justicia que tuviera que contradecir las filosofias del consenso racional. De hecho, desde ahora confieso mi adhesión a muchas ideas -si no a todas, como veremos- de la teoría de Rawls. Pero mi punto de partida sería distinto. Pienso que toda reflexión ética auténtica se funda, en último término, en un conocimiento personal, diferente al saber objetivo. Las proposiciones en que se justifica no son, por lo tanto, incontrovertibles. Pero el conocimiento personal de la presencia o ausencia de valores en el mundo en torno debe ser sometido a una crítica racional, para llegar a proposiciones aceptables razonablemente de mane- 
ra intersubjetiva. ${ }^{1}$ La injusticia es una carencia experimentada de valor objetivo; de esa experiencia puede partir la proyección, basada en razones, de una situación posible en que se daría ese valor. Se puede llegar así a una teoría de la justicia fundada en esa experiencia específica de una carencia concreta, padecida por sujetos situados socialmente. Esta vía no implica que la teoría a la que conduzca contradiga necesariamente las filosofías fundadas en un consenso racional. Los distintos enfoques propondrían puntos de vista alternativos que podrían presentar puntos semejantes. El mismo edificio, visto desde la azotea aparece con una traza distinta si se contempla desde la acera, pero su estructura es la misma. Tal vez esas visiones complementarias de la justicia pueden revelar matices, caracteres que resalten más en una que en otra.

$Y$ confieso un deseo oculto. Al insistir en la experiencia de la injusticia antes que en el consenso, quisiera presumir de que establezco alguna analogía con la "alternativa del disenso" propuesta por Javier Muguerza para fundar los derechos humanos, ${ }^{2}$ aunque mi pretensión sea más limitada, porque no es la fundamentación de los derechos humanos, sino la caracterización de los principios de justicia en una sociedad, aún si no tiene todavía conciencia del carácter universal de esos derechos.

II

Las teorías que hacen depender de un consenso nuestro conocimiento de la justicia se enfrentan a dificultades, en mi opinión insalvables.

Si por "consenso" entendemos el acuerdo efectivo que, de hecho, expresa la mayoría de los miembros de una asociación, ese consenso no sirve para nuestro propósito. Una sociedad puede estar de acuerdo con la discriminación de un grupo de individuos frente a otros o con la imposición del bien de un grupo sobre el de los demás. Muchos autores han señalado la imposibilidad de fundar el valor objetivo de la justicia en un consenso fáctico. No repetiré sus argumentos. Me limitaré a precisar en qué consiste, a mi juicio, esa imposibilidad.

La justicia es, por principio, un valor objetivo. La objetividad de un valor, en un conocimiento personal, no consiste, por supuesto, en su realidad independiente del sujeto, pues todo valor es el término de actitudes de sujetos concretos. Tampoco es condición de su objetividad el que tenga una validez incontrovertible, es decir, no sujeta a falsación, como es el caso de la objetividad exigida por las proposiciones científicas. El criterio para aceptar la objetividad de un valor es que pueda ser término de una actitud positiva de cualquier

${ }^{1}$ En El poder y el valor. Fundamentos de una ética política, Fondo de Cultura Económica México 1997, he expuesto una concepción ética basada en un conocimiento personal, sometido a crítica.

${ }^{2}$ Cfr. Javier Muguerza, Ética, disenso y derechos humanos, Argés, Madrid, 1998. 
sujeto de una comunidad determinada, que responda, por lo tanto, al interés real de todo sujeto y no sólo al interés particular de un individuo o grupo social. Un valor objetivo es pues benéfico para todos los individuos de una asociación ${ }^{3}$.Ahora bien, el consenso efectivo puede pretender que su idea de justicia tiene un valor objetivo pero fracasa en fundar esa pretensión. En efecto, no puede demostrar que su noción de justicia corresponda al interés de todos.

Porque un consenso efectivo puede ser el resultado de la aceptación forzada por muchos individuos de una situación que en realidad no les beneficia, ya sea por imposición social, por represión política o por ceguera o engaño. Los valores consensuados serían entonces los que satisfacen intereses particulares de un grupo dominante y no los que responden a necesidades generales. En un consenso de hecho, cada quien sigue sus intereses particulares; por consiguiente, su resultado depende de la fuerza relativa que tengan los intereses en juego; el consenso efectivo reflejará el equilibrio al que pueden llegar los componentes de la asociación con intereses opuestos. El consenso efectivo supone sujetos con valores particulares en competencia; los que triunfen no son necesariamente coincidentes con los valores sostenidos por los demás; luego, pueden ser excluyentes de los otros.

Ensayemos entonces otra hipótesis. No hablemos ya de un consenso efectivo, pensemos en un consenso hipotético entre sujetos racionales. Este tendría que cumplir tres condiciones contrarias a las fallas que indiqué para el consenso fáctico: 1) Los sujetos de ese consenso serían racionales y libres. 2) No se regirian por intereses que pudieran excluir los de otros. Los valores consensuados no resultarían, así, del éxito de las estrategias que cada quien pusiera en juego para su propio beneficio, sino de la voluntad de llegar a un bien común. 3) En el acuerdo consensuado no intervendría la coacción del poder. Al contrario de los consensos fácticos, éste tendría que ser un convenio entre individuos iguales, no sujetos a coacción y que siguieran principios racionales.

Para llegar a ese consenso racional hipotético, pueden seguirse varios caminos. Recordaré sólo dos, por tratarse de los más influyentes en la actualidad: los de John Rawls y de Jürgen Habermas.

Las dos vías difieren en muchos puntos pero tienen otros en común. En ambas, el convenio se considera obra de sujetos libres y racionales. En Rawls, el sujeto tras el velo de la ignorancia, al desconocer su rol específico dentro de la sociedad e incluso el sistema asociativo al que pertenece, elimina todos los intereses particulares ligados a una situación específica en el sistema, que pudieran oponerse a los de sujetos en otra situación; en consecuencia, sus intereses son los que convendrían a cualquiera en cualquier situación. Gracias a esa hipótesis, en la "posición original" los sujetos no pueden calcular su beneficio siguiendo intereses excluyentes de otros sujetos que estuvieran en otra situación. El "velo" cumple pues una única función: reducir el cálculo

\footnotetext{
${ }^{3}$ Cfr. El poder y el valor, Op cit, cap. 2.
} 
interesado de cada sujeto a intereses que no se contrapongan con los de cualquier otro sujeto en otra situación posible. Elimina pues los intereses que excluyan a los otros en las distintas posiciones que pudieran ocupar.

En Habermas la hipótesis es distinta. Se supone un diálogo no coactivo, entre sujetos que se atienen a argumentos racionales. Pero racional es justamente un argumento cuando no se acepta por simple presión ajena y cuando no está sesgado por prejuicios ni por intereses contrarios a lo realmente benéfico para cualquiera. Racional es una argumentación que sólo intenta justificarse en razones no impuestas y comparables por todo sujeto pensante. Una voluntad racional, piensa Habermas, tiene que ser educada; el objetivo de esa educación es llegar de acuerdos entre sujetos que no basen sus elecciones de valor en intereses individuales, no universalizables.

Los dos caminos tienen una función teórica semejante: postular como agente del consenso un tiempo especial de sujeto. Tanto en la "posición original" de Rawls como en la " comunidad racional de diálogo" de Habermas, los sujetos del consenso tendrían las siguientes características: 1) Se determinarían por su propia razón, sin seguir dictados ajenos. 2) No se guiarían por un interés particular, excluyente del de otros sujetos. 3) Su acuerdo no dependería del poder mayor de un sujeto o grupo sobre los demás; todos tendrían, por ende, igual libertad. Un sujeto racional que se guía por valores objetivos y es libre de obrar o no obrar conforme a esos valores es un sujeto moral. Creo que puede interpretarse la propuesta del convenio hipotético como una operación teórica para fundar el valor común de la justicia en las elecciones que haría ese tipo de sujeto. En esa operación cumple su función.

Ahora bien, las dos vías siguen una ficción. Se figuran los principios de una sociedad justa como si fueran el resultado del conciliábulo de sujetos de ese tipo; como si, para saber los caracteres de la justicia, tuviéramos que esperar el consenso al que llegarían un conjunto de individuos libres y racionales. Pero eso es sencillamente imposible. No podemos tener acceso a la totalidad de elecciones de los sujetos racionales ni, por lo tanto, al consenso que resultaría de su interlocución. Este es sólo una hipótesis en la mente de un sujeto racional, fraguada por él. Es él quien, después de hacer a un lado sus intereses excluyentes y considerar lo conducente al bien de cualquiera en cualquier situación, concibe lo que podría ser la elección de una comunidad imaginaria de sujetos semejantes a él. El consenso hipotético deriva, por lo tanto, de la previa posición de un sujeto individual y no a la inversa. El sujeto moral no necesita del consenso para saber cuáles son los valores comunes; al contrario, a partir de la actitud personal hacia valores objetivos, imagina lo que sería un consenso inexistente. $\mathrm{Al}$ pretender que el valor de su elección es objetivo, pretende también que cualquier otro sujeto racional, que tomara la misma actitud, coincidiría en la elección del mismo valor. Pero entonces el consenso hipotético no funda el valor común (es decir, no justifica racionalmente su pretensión de objetividad); al contrario, la actitud racional del sujeto individual, en la medida 
en que elimina de su elección los intereses excluyentes, hace posible figurar las características de un consenso racional.

En las dos propuestas teóricas que consideramos, para lograr la ficción de un consenso racional, el pensador imagina una situación de comunicación entre sujetos irreales. Se figura personajes extraños que hayan olvidado cualquier elemento de su situación real y desconozcan la postura que desde niños han ocupado, vacíos de toda característica diferencial, sin atributos sociales predicables: ésos son los personajes que se supone subsisten detrás del "velo" de Rawls. O bien son hombres y mujeres capaces de dialogar y elegir algo, sin ninguna influencia de las pasiones y deseos que los identifican, como imagina Habermas. Ninguno de esos personajes existe; más aún, ninguno puede existir. Porque son fantasmas despojados de lo que los hace ser miembros de una asociación. El consenso hipotético se realiza entre sujetos que, por principio, no pertenecen ya a ninguna asociación. Las críticas de algunos autores calificados de "comunitaristas" no carecen de razón; sólo personas concretas, situadas en un contexto social, regidas por razones pero también por pasiones, pueden realizar convenios, porque sólo ellas son agentes morales, capaces de elegir con libertad.

Sin embargo, a mi juicio no debemos rechazar del todo la ficción del consenso racional hipotético; sólo reducirla a la función teórica que cumple. Como acabo de decir, su función es hacernos ver que el valor objetivo, común a todo miembro de la asociación, no es el que se presenta a un individuo situado cualquiera, sino a aquellos que hagan a un lado sus intereses excluyentes y rijan sus elecciones por un interés general. Nos indica que, para descubrir un valor objetivo, -la justicia, en este caso-, es menester una conversión de la voluntad: el paso de una voluntad en busca de su beneficio exclusivo a una voluntad des-prendida de propósitos excluyentes. Pero si la hipótesis se restringe a esa función teórica, no es preciso despojar de sus caracteres identitarios a los sujetos, ni pensarlos desprovistos de su situación social. Tampoco es necesario imaginar un convenio ficticio entre ellos, ni deducir cuál sería su resultado. Lo que sí se requiere es distinguir en cualquier sujeto las actitudes y elecciones de valor variables en cada persona, de las elecciones de valor de ese mismo sujeto si actúa desprendido de sus intereses particulares excluyentes. Esos valores serian, en principio, comunes a todos los miembros de la asociación. Pero, para saberlo, no podemos esperar su acuerdo, pues sólo tenemos acceso a nuestras propias razones y en ellas debemos poder fundar nuestra pretensión de objetividad.

\section{III}

Emprendamos pues otro camino. Partamos del hombre y la mujer situados, pertenecientes a una sociedad y a una cultura, con una posición y una identidad en ella. Preguntémonos: Primero ¿cuáles son las condiciones para que ese sujeto llegue a concebir valores comparables por cualquiera, que no respondan 
solamente a su interés individual y no excluyan los intereses ajenos? Segundo ¿qué caracteres mostrarían ante ese sujetos, esos valores? No pretendemos que la objetividad del valor - en este caso, de la justicia- se funde en un consenso previo (así fuera hipotético), preguntamos, por el contrario, cómo deducir la posibilidad de un consenso racional de la conversión de la voluntad de un sujeto situado.

Ahora bien, la situación de todo sujeto comprende la existencia, de hecho, de un previo consenso social de raíces históricas. Porque, desde su nacimiento, el individuo está inmerso en un mundo social que imprime en su comportamiento usos y costumbres establecidos, y en sus creencias e intenciones, preferencias consensuadas. Éstas se expresan en reglas, tácitas o proclamadas, cuyo cumplimiento permite la realización de virtudes aceptadas. Los distintos individuos y grupos difieren en una pluralidad de elecciones y concepciones acerca de los valores a seguir. Aún así, en la medida en que se mantiene cierta unidad en el todo social, un conjunto de creencias y reglas de conducta, aceptadas por una mayoría dominante, constituye un cemento capaz de mantener coaligadas las diversidades. Es parte de la Sittlichkeit de los filósofos alemanes, que algunos autores traducen (erróneamente, en mi opinión) por "eticidad". Prefiero referirme a ella como "moralidad social" . La moralidad social constituye un objeto de consenso efectivo, mayoritario. Por la educación y el reconocimiento social, el individuo sigue ese consenso sin tener que ponerlo en cuestión. En el seno de la moralidad social existente, la persona adquiere las actitudes que permiten una convivencia ordenada y una colaboración recíproca; hace coincidir así sus impulsos egoístas con actitudes de beneficio a la comunidad. En la moralidad consensuada, sin necesidad de crítica, el individuo se socializa; al socializarse, desarrolla una primera dimensión moral.

Las reglas de la moralidad social constituyen sistemas normativos que regulan los comportamientos de la mayoría de los miembros de la sociedad. Podemos interpretar el consenso fáctico como un pacto tácito de convivencia entre la mayoría de los sujetos sociales. El concepto de la justicia vigente es resultado de ese acuerdo tácito.

Pero toda idea de justicia presenta dos caras: por un lado, es un bien común a los sujetos de la asociación, por el otro, acepta ciertas diferencias entre esos sujetos, al normar un trato equitativo de ellas. En una comunidad de consenso, varía tanto el contenido del bien común consensuado como las diferencias admitidas. La idea de justicia que, de hecho, priva en cada sociedad, establece una doble demarcación: por una parte, separa el conjunto de sujetos que otorgan su consenso a un bien común, de los excluidos de ese consenso; por otra parte, delimita las diferencias que merecen un trato equitativo frente a las diferencias inaceptables. Sujetos del consenso social son los que coinciden en la aceptación de los valores comunes, se rigen por ellos y son agentes del acuerdo tácito en que se basan; son los que sostienen sin disentir, las normas de la moralidad vigente. Podríamos llamarlos, por lo tanto, los "sujetos 
normales" de la asociación. El concepto de justicia vigente se adecúa a su patrón de "normalidad". Entre los sujetos del consenso social existen diferencias notables de posición social, de recursos y bienes, de creencias y valoraciones; pero el sentido de justicia consensado establece las diferencias susceptibles de ser tratadas con equidad por la sociedad frente a las inadmisibles. Responde por lo tanto, a ciertas preferencias particulares y no deja de rechazar otras.

La comunidad de consenso social no coincide necesariamente con el conjunto de sujetos que determinan el sistema de asociación política al que pertenecen y participan en su funcionamiento. Entre los sujetos del consenso social, otro conjunto determina no sólo el consenso moral sino también la forma del dominio político. Siguiendo la metáfora tradicional, podríamos hablar de los agentes del pacto político.

Comunidad de consenso social y sujetos del pacto político no coinciden siempre. Por ejemplo, en la Atenas de Pericles, las mujeres y los metecos aceptan las reglas del consenso social, pero no son agentes del pacto político, por no ser ciudadanos. A la inversa, en muchas sociedades ciertos grupos marginados pueden ser considerados miembros del pacto político, por ser reconocidos como ciudadanos, pero estar al margen del consenso social, por padecer discriminación. La exclusión de una persona o de un grupo puede, por lo tanto, tener dos niveles. Puede ser excluida del conjunto de personas que aceptan el consenso social o bien de las que determinan el pacto político. En ambos casos el excluido, aunque tenga todas las características de un agente moral, deja de pertenecer a una comunidad de consenso, sea ésta social o política.

Por ejemplo, en las monarquías católicas del Medioevo europeo, los diferentes súbditos del rey y fieles de la Iglesia son "sujetos normales", pues pertenecen a la comunidad de consenso social y comparten su idea de justicia; quedan fuera, en cambio, los anormales, esto es, los que difieren en creencias religiosas (herejes o paganos) o subvierten las instituciones monárquicas. En las colonias españolas del Nuevo Mundo, los indios están excluidos de la comunidad de consenso establecida, española-criolla, pues no comparten plenamente su cultura ni son tratados como iguales; las "castas", en cambio, sólo son marginadas del pacto político, pero aceptan el consenso social mayoritario. En las primeras repúblicas burguesas, sujetos del pacto político son el conjunto de individuos varones con un mínimo de propiedad, no así los que difieren en género o carecen de bienes; en cambio, muchos de estos últimos pueden prestar su consenso a las normas del concepto vigente de justicia.

Tanto en el ámbito del consenso social efectivo como en el del pacto político, sei establece una demarcación entre una comunidad de sujetos considerados "normales" y un margen de excluidos. En este espacio puede manifestarse un disenso. 
Hasta aquí nos hemos asomado a la pretensión de una idea de justicia basada en un consenso efectivo. Pero la moralidad social constituye sólo un primer nivel, precrítico, de la ética. La ética critica empieza cuando el sujeto se distancia de las formas de moralidad existentes, de sus usos "normales", y se pregunta por la validez de sus reglas y comportamientos. Puede percatarse entonces de que la moralidad social no cumple las virtudes que proclama o bien ignora otras más altas. La persona puede poner en entredicho la validez de los principios y reglas aceptados de la mayoría, los cuales remiten a una tradición y se reafirman en su fidelidad a ella. Entonces puede percibir en el orden social una carencia: la ausencia de la realización social de ciertos valores objetivos. La percepción de esa falla puede convertirse en un rechazo de la moralidad social vigente y de su idea de justicia. Puede ser un movimiento de retorno a una tradición que se considera adulterada por la moralidad social consensuada: es entonces una recuperación de valores proclamados pero no cumplidos, una exigencia de autenticidad, un retorno al origen. Puede ser también la crítica de los valores aceptados y de la idea de justicia en curso y una postulación de valores otros, que se consideran superiores; en este caso, el rechazo de la tradición puede ser más o menos completo. En cualquiera de los dos caminos se postula otra idea de la justicia, conforme a la razón; su origen está en ese movimiento disruptivo frente al consenso establecido en el ámbito de la moralidad social vigente.

Podríamos advertir, en ese proceso, cuatro etapas, que se sobreponen y coinciden a menudo, pero que podemos distinguir por mor de la claridad:

1) La experiencia de la exclusión. Ella provoca la conciencia de la separación tajante entre los sujetos excluidos y la comunidad de consenso social o resultante del pacto político.

2) El juicio de la exclusión como injusticia. La consideración de la injusticia obliga a rechazar la pretensión de objetividad de la noción de justicia comúnmente aceptada.

3) La construcción de un nuevo sujeto moral. El excluido se autodetermina como agente libre frente a la comunidad que lo rechaza.

4) La proyección de un nuevo modelo de justicia. Este implica, a la vez, la caracterización de un sujeto moral frente al sujeto "normal" de consenso y nuevos principios de justicia válidos para ese sujeto moral.

De hecho, es este el proceso que, según nos narra la historia, individuos y grupos sociales han seguido para llegar a una concepción cada vez más racional de la justicia, capaz de ser universalizada.

De la experiencia personal de la exclusión de los indios en América nace, en un Las Casas, la indignación ante la injusticia y, de allí, la postulación de un trato equitativo hacia el colonizado, como un sujeto moral que implicaría 
una idea superior de justicia. La exclusión del "Tercer Estado" respecto del pacto político conduce en la Revolución Francesa, a la revelación de la injusticia del Antiguo Régimen; esa experiencia tiene otra cara: la postulación de un orden racional de justicia incluyente de todo agente moral autónomo, cualquiera que sea la clase social a la que pertenezca. Y sólo la dolorosa experiencia de la explotación de los desposeídos pudo conducir, en los dos últimos siglos, a la concepcion teórica de una justicia económica y social que abarca la equidad en la distribución de bienes y oportunidades sociales para todos.

Veamos primero en qué consiste, en todos los casos, la experiencia personal de la exclusión. Digo "experiencia personal" porque, en efecto, se trata de un conocimiento directo por el individuo, ya sea del rechazo del que él personalmente es objeto, ya de la comprobación de la exclusión a que están sometidos otros individuos o grupos con los que mantiene contacto. No se trata de un rechazo general, sino de una relación vivida en el seno de una sociedad concreta.

La comunidad de consenso está constituida, en cada caso, por personas que tienen ciertas características definidas. Esas características son el criterio para que una persona sea aceptada y, por ende, pertenezca plenamente a la comunidad. Los excluidos, en cambio, lo son por poseer alguna diferencia que los coloca aparte de los sujetos "normales". En ese respecto preciso no pueden ser aceptados, aunque puedan serlo en otros aspectos. Ante la comunidad de "sujetos normales" los excluidos ya no son considerados sujetos como ellos; son vistos desde fuera, determinados por los juicios de los otros; quedan "cosificados" por la característica que los vuelve rechazables. La diferencia que hace a los excluidos inaceptables para la sociedad puede variar en cada contexto histórico. En todo caso es esa nota diferencial (raza, género, ascendencia, pertenencia a una clase o etnia, etc.) la que los descarta del consenso efectivo. La comunidad de consenso no puede tomar en cuenta sus preferencias; al no considerarlos sujetos iguales; tampoco puede admitirlos como interlocutores del pacto político, salvo en los aspectos que no toquen a esa diferencia. "Tu no puedes intervenir en nuestro acuerdo", parece decirle, "No eres uno de nosotros". La comunidad de consenso los "ningunea" -si se me ha de permitir el mexicanismo- es decir, los considera un "don nadie", no apto para acordar con los otros porque está determinado por ellos.

La exclusión se da siempre ligada a una diferencia determinada del excluido y a un aspecto concreto del bien o relación social de la cual se le excluye. La comunidad de consenso no coincide con otra comunidad más amplia posible que abarcaría igualmente a las personas con la diferencia excluida. La experiencia de la exclusión consiste en la comprobación personal de esa falta de coincidencia entre una comunidad de consenso, formada por sujetos "normales", y esa otra comunidad posible, de sujetos capaces de decisión libre.

$\mathrm{Al}$ experimentar la exclusión comprobamos que la moralidad consensuada no realiza valores objetivos, puesto que descarta las preferencias de los excluidos. 
Su idea de justicia no incluye de la misma manera a todos, responde sólo al interés de algunos. La experiencia de la exclusión es así, la percepción de una ausencia: la de un valor objetivo. Se constata que la pretensión de validez de la idea consensuada de justicia no se sostiene. La experiencia de la exclusión ha abierto al conocimiento personal de la injusticia.

Sin embargo, el paso de la experiencia de la exclusión al conocimiento de la injusticia no es automático. Porque a menudo el excluido opone a la comunidad de consenso su propio interés particular, igualmente excluyente de los demás. Es el caso de criminales y explotadores, pero también de grupos disidentes o rebeldes que, en vez de regirse por valores comunes, establecen, a su turno, la exclusión de los grupos contrarios. El resentimiento y la venganza del rechazado no le permiten entonces acceder a una nueva idea de justicia. No puede así comprender su propia exclusión como ausencia de esa justicia.

Pero otras veces el excluido afirma el valor objetivo, válido para todos, del respeto a su diferencia. Su disrupción se traduce en una exigencia: la demanda del respeto común a su concepción y elección de valores y a sus necesidades diferenciadas, aunque una y otras se aparten de las aceptadas de hecho. La exigencia se presenta, en el aspecto normativo, como postulación de un derecho a su diferencia, derecho a participar en el aspecto concreto de la vida social o política del que fue excluido.

Hay que distinguir, por lo tanto, entre un disenso que no justifica un juicio sobre la injusticia existente y otro que lo fundamenta. El paso de la experiencia personal de una exclusión a la conciencia de una injusticia no es automático. Supone una crítica racional del rechazo experimentado, que lleva a la conclusión de que la inclusión de la diferencia rechazada es un valor objetivo y no responde simplemente a intereses a su vez excluyentes. Las Casas discute de la exclusión de los indios de la comunidad de consenso aceptada, porque demuestra - basado en argumentos racionales- que son agentes morales iguales a los españoles. Los encomenderos españoles, por su parte, se sienten dañados en sus intereses por cualquier medida que los igualaran con los indios y disienten de las leyes que pretenden protegerlos. ¿Cuál es el criterio que permite distinguir entre estas dos formas de disenso?

Justicia es un valor común. Luego, sólo podemos concluir a una injusticia si a alguien se le rechaza el acceso a ese valor común. Debemos demostrar, por lo tanto, que el excluido tiene el mismo derecho que el excluyente a un trato justo. Mientras no lo hagamos, no podemos concluir correctamente de la experiencia personal de la exclusión a una injusticia. En cambio, no forman parte de las normas de justicia, leyes o prácticas que concedan a un grupo imponer su interés sobre el de los otros. La falsa universalización del propio interés es una operación ideológica, al servicio de un poder particular: la reivindicación del excluido por ser igual a los sujetos de consenso aceptados, afirma en cambio un valor común. Por ello, debe demostrar que el excluido es un sujeto con los mismos derechos que los que lo excluyen y que su aceptación forma parte de un valor común. 
Definimos la exclusión como la falta de coincidencia entre la comunidad de consenso efectiva y otra comunidad posible de agentes morales. Ni el criminal ni el encomendero pueden considerarse excluidos en ese sentido. Al pretender un estatuto universal para sus intereses particulares, su posición es, por lo contrario, excluyente de quienes no comparten ese interés.

El excluido, al cobrar conciencia de la falta de coincidencia entre la comunidad de consenso, social o político, y otra comunidad posible que incluyera su diferencia, construye un sujeto moral nuevo, porque está dirigido por un interés general desprendido de su propio deseo de descartar a los demás, dirigido por valores comunes benéficos incluso para los sujetos del antiguo consenso. Ese nuevo sujeto moral no prescinde de su identidad personal, puesto que reafirma su diferencia. Es un sujeto situado en un contexto especifico y sólo gracias a su situación puede acceder al conocimiento personal de una nueva idea de justicia.

Las Casas experimenta la exclusión en la opresión de sus prójimos, los indios, porque ellos son diferentes a las variantes aceptadas en la comunidad consensuada de españoles. Comprende que la injusticia del régimen colonial descansa en el interés particular, no generalizable, de los dominadores. Entonces discrepa: tan sujeto moral es el indio como el español; debe exigir el mismo reconocimiento como miembro igual en la asociación; ese reconocimiento lo igualaría, por lo tanto, a los demás en un respecto: como súbdito del soberano, con las mismas prerrogativas, y como fiel de la misma Iglesia. Asî las características de ese nuevo sujeto moral están determinadas por la situación a la cual responde; son la negación de una exclusión específica. Las Casas y sus seguidores incorporan en la idea del sujeto moral, digno de justicia, la diferencia de raza, origen de la exclusión, pero no incluyen en ella otras diferencias que le dan identidad, la de creencias religiosas y de prácticas mágicas, por ejemplo; pues Las Casas sigue aceptando como único valor religioso objetivo la doctrina católica. El indio tendrá derecho, pese a su diferencia de raza, de ser un súbdito igual al español, pero no de ser diferente en otros rasgos, aún inadmisibles: en la afirmación de su libertad política, por ejemplo, o de sus creencias "heréticas". La nueva noción de justicia será más racional, porque ampliará el círculo de las diferencias admitidas; consistirá en la no-exclusión del rasgo identitario rechazado en el aspecto en que fue rechazado, pero podrá seguir manteniendo el rechazo de otras diferencias, en otros aspectos.

Más tarde, Locke experimentará otra forma de exclusión: la intolerancia religiosa. Ella lo llevará a precisar otro aspecto de la injusticia que, durante mucho tiempo estaba oscurecido. Proyectará entonces un nuevo sujeto moral que incluirá la virtud de la tolerancia; ampliará así el círculo de las diferencias que no deben ser objeto de repudio; abrirá el campo de las opciones y creencias privadas entre las diferencias que merecen ser aceptadas en el trato equitativo de la justicia. Pero aún él dejará pendiente la posibilidad de una comunidad de consenso que excluyera otras discriminaciones en otros aspectos de la relación social, por ejemplo, las que derivan de la propiedad o aún de la ascendencia. 
Los revolucionarios del siglo XVIII experimentan la exclusión del Tercer Estado respecto del poder político. Esa experiencia se acompaña, en la reflexión, de la construcción de un agente moral nuevo: el sujeto universal de " derechos humanos", que incluye las exigencias de equidad de aquel Estado. Su nueva idea de justicia abarcará los derechos individuales de todo ciudadano, en los aspectos en que antes era excluido; sin embargo, permitirá aún la exclusión de grupos con diferencias económicas y sociales; ellas darán lugar a nuevas exclusiones... y a nuevas disrupciones posteriores frente a una sociedad injusta.

Cada experiencia de exclusión de una diferencia determinada en un aspecto de las relaciones sociales, permite oponer a la comunidad de consenso una idea del sujeto moral que no rechace esa diferencia específica en ese aspecto particular. Pero esa idea puede comprender aún otros rechazos de diferencias, que pueden hacerse patentes en experiencias sociales posteriores. La idea de justicia se va enriqueciendo al tenor de la progresiva conciencia de las injusticias existentes.

Porque, en cada caso, la comprobación de una injusticia conduce a la proyección intelectual de un orden social más justo. Ese orden nace de una disrupción de un consenso fáctico anterior y conserva las características peculiares de esa disrupción. Su carácter objetivo no puede fundarse, por lo tanto, en ese consenso. Se justifica en el conocimiento personal sometido a critica, de una injusticia padecida. Pero, a partir de ese conocimiento personal proyecta la posibilidad de un orden social, en que no existiera la exclusión específica contra la que el discrepante se rebela. El nuevo orden estaría constituido por la decisión de sujetos morales que incluyen las diferencias antes inadmisibles, pero no está libre de no incluir otras diferencias, de las que aún no hay conciencia. Podríamos pensar entonces ese nuevo orden como producto de un consenso hipotético entre esos sujetos morales. Notemos, sin embargo, que ese consenso imaginario es sólo una figuración en la mente del sujeto moral y funda su validez en su conocimiento personal.

Las Casas sueña con una monarquía católica que gobernara con equidad tanto a indios como a españoles, pero no a herejes o a rebeldes al soberano. Locke proyecta una sociedad tolerante frente a las diferencias de creencias, pero su idea de justicia no comprende el trato equitativo de todos en las funciones de decisión política. Rousseau y Kant levantan la idea de una sociedad respetuosa de todas las libertades privadas y de los derechos políticos iguales de todos los ciudadanos, pero no incluyen en su idea de justicia la igual distribución de bienes y servicios. En cada ocasión, la ampliación de la equidad en ilas diferencias está determinada por un tipo de exclusión que merece rechazarse.

Concluyamos

1) Para llegar a una concepción racional de la justicia podemos partir de las experiencias del hombre y la mujer concretos, situados en un contexto social. Frente a la moralidad consensuada y su idea de justicia surge la posi- 
bilidad de una ética crítica. El discrepante parte de la percepción de una injusticia y proyecta un orden social distinto. La situación proyectada es la no-excluyente del tipo de diferencia antes repudiado. El disidente puede desprenderse de su interés excluyente y exigir un orden donde rigiera un interés general.

2) El disidente puede construir un nuevo sujeto moral distinto al sujeto "normal" de la moralidad en curso. Puede postular entonces la coincidencia de la comunidad de consenso con una comunidad posible de sujetos morales, en que ningún sujeto moral quedara descartado.

3) Los principios de justicia racionales no se derivan del consenso de los sujetos morales; se fundan en una conversión de la voluntad del sujeto, que pasa, de obedecer a intereses particulares ajenos, a determinarse a sí mismo, por un interés general, no excluyente.

4) La construcción del sujeto moral está determinada por la negación de un tipo especifico de exclusión y por el reconocimiento de una diferencia. Estos pueden variar en cada caso. Por eso la idea de justicia a que se llegue a cada momento histórico de disrupción lleva la marca de la situación que dio lugar a la disrupción. De parecida manera, las diferencias que el disidente acepta en su nueva idea de justicia dependerán del tipo de diferencias que fueran objeto de exclusión en la situación histórica contra la que se rebela. Las concepciones del sujeto moral se enriquecerán conforme se amplíe el margen de las diferencias aceptadas y se restrinjan las exclusiones posibles. De la misma manera, las exigencias de los sujetos morales, que deberían traducirse en derechos al ser reconocidas por el Estado, se ampliarán también en el mismo proceso. El reconocimiento progresivo de distintas "generaciones" de derechos humanos da testimonio de esta evolución.

La vía que hemos seguido no es inocua. Pretende situar la caracterización de los principios de justicia en un proceso histórico cuyos agentes son personas reales, situadas en un contexto, que parten de una moralidad social dada para ponerla en cuestión. Creo que responde al camino que efectivamente los hombres han recorrido y continúan recorriendo en la historia, en su perpetuo acercamiento a la justicia.

Ese punto de vista me permitirá contemplar una teoría contemporánea de la justicia bajo una luz que arrojará, espero, nuevos matices a su trama. Ese será el tema de la conferencia siguiente.

\section{EXCLUSIÓN, LIBERTAD E IGUALDAD}

En la conferencia pasada traté de rastrear los orígenes de la noción de justicia en la percepción inicial de una exclusión. La exclusión señala como causa el poseer alguna diferencia. Luego, la eliminación de la exclusión consistiría, 
en cada caso, en la eliminación de un trato diferenciado. Podemos llegar así a una primera formulación de la idea de justicia como "igualdad en las diferencias". Conviene ahora detenernos en este concepto.

La idea prereflexiva que todos tenemos de la justicia la asocia con igualdad. $\mathrm{Su}$ representación simbólica sugiere esa asociación de ideas. La justicia es imparcial porque es ciega ante las diferencias y el fiel de la balanza que sostiene está siempre en equilibrio.

Pero no se trata de la igualdad entre objetos o personas que compartirían las mismas propiedades. Entre $x$ e $y$ puede establecerse una igualdad si a ambos se les puede atribuir las propiedades $a, b$ y $c$. En ese respecto son iguales, aunque difieran en otras propiedades; pertenecen pues a la misma clase lógica, definida justamente por las notas $a, b$, y $c$. Conforme a este tipo de igualdad, quienes la comparten pueden considerarse sujetos homogéneos; en ese respecto, pueden ser intercambiables. Para entendernos, llamemos "igualdad sustantiva" a esa forma de igualdad.

Pues bien, la justicia no corresponde a ese género de igualdad. Iguala a varias personas, pero no por atribuirles propiedades comunes, sino por aplicarles la misma pauta o regla. Las personas en cuestión pueden ser diversas en todas sus propiedades sustantivas. Otorgar en una competencia el primer premio a quien llegue en primer lugar es una regla justa si se aplica a todos los competidores por igual, por más que su fin sea establecer una diferencia entre el ganador y los demás. La regla podría cambiar; estatuir, por ejemplo, que el tercero en llegar a la meta fuera considerado vencedor; en ese caso, aunque sería más difícil de cumplir, seguiría siendo justa si se aplicara a todos los corredores, por distintos que pudieran ser en otros aspectos. Supongamos que, en una escuela, es costumbre que todos los niños reciban un caramelo al terminar las clases; la medida es justa si no hace acepción de personas, no lo es, si deja a un lado a los tres niños diferentes por ser los más feos o los más chaparros. La justicia no establece una igualdad de propiedades sino una igualdad de trato, igualdad en la aplicación de una regla a personas y situaciones diferentes. Para distinguirla de la "igualdad sustantiva", llamemos "equidad" a la aplicación de ese criterio de igualdad. Si la igualdad sustantiva se resuelve en homogeneidad, la equidad admite lo heterogéneo.

La equidad marca ciertos criterios de pertenencia de distintos elementos a un todo, al considerar reglas aplicables solamente a ese todo. El seguimiento de las mismas reglas de competencia marca la pertenencia al conjunto de personas participantes en una contienda deportiva; la equidad en la distribución de dulces se aplica sólo a los alumnos pertenecientes a la misma escuela. La pertenencia iguala a las personas diferentes. El rechazo de alguna diferencia es también negación de pertenencia. A la inversa, la negativa a una persona o a un grupo de pertenecer a una comunidad, implica una desigualdad en la aplicación de las mismas reglas. La exclusión consiste en negar a la vez equidad y pertenencia a quienes tengan alguna diferencia. 
La diferencia que determina la exclusión puede ser una característica que no se origina en la exclusión misma, sino la provoca; por ejemplo, la raza, la etnia, la ascendencia, o bien las opiniones, creencias y actitudes diferentes a lo aceptado. Pero también puede ser una situación desigual en la distribución de bienes y servicios o en el acceso a oportunidades, que genera a su vez una diferencia. En el primer caso, la diferencia causa una exclusión, en el segundo, la exclusión engendra una diferencia. Esas son las dos caras de la injusticia.

Las Casas comprueba cómo la diferencia de sangre y de cultura es causa de que los indios no se consideren pertenecientes a la misma comunidad que los españoles. Esa exclusión origina una desigualdad material en la situación económica y social de los indios. Y esa desigualdad es vista, a su vez, como diferencia que debe ser excluida. Ya no sólo se descarta al indio por ser indio sino por tener una situación económica y social inferior. En una sociedad moderna, la exclusión puede referirse a una diferencia de opinión o de actitud y dejar fuera a los discrepantes, pero también puede tomar como muestra de una diferencia rechazable la desigualdad económica y social, auspiciada por exclusiones anteriores, negándoles igual pertenencia social a los desiguales en educación o en propiedad, En este segundo caso, una desigualdad originada en una exclusión, se toma a su vez como diferencia justificante de exclusión.

Las desigualdades materiales existentes en una sociedad pueden verse, en efecto, como diferencias que excluyen. Las deficiencias en alimentación, en cuidado a la salud o en educación, en regiones pobres, son generalmente el resultado de su marginación en el sistema social y político del que forman parte y provocan, a su vez, características diferenciadas de los pobres que los excluyen del resto de la población. La pobreza en general se ha podido definir como exclusión del acceso a bienes y servicios o aún como la expulsión de la pertenencia a formas de vida consensuadas en la comunidad ${ }^{4}$.

Muchas desigualdades no son el resultado de una exclusión actual, sino de marginaciones variadas anteriores. Muchos miserables lo son por haber nacido en situaciones en que ni sus padres ni los padres de sus padres gozaron de su parte equitativa en la distribución de bienes y oportunidades. Su situación hereda una exclusión histórica.

Tratar a los desiguales como personas rechazables por diferentes es prolongar las exclusiones que les dieron origen. Por ello la justicia implica la eliminación de las desigualdades originadas en el repudio de diferencias o, dicho de otra manera, la rectificación de las exclusiones históricas anteriores que dieron lugar a desigualdades. De allí que, como veremos, una acción justa implica un trato desigual a los desiguales. Pues tan injusto es tratar igual a los desiguales como tratar de modo desigual a los iguales.

\footnotetext{
${ }^{4}$ Peter Tawsend, International Analysis of Poverty.
} 
En la conferencia pasada insistimos en la evolución histórica de la idea de justicia. Las Casas experimenta el rechazo, en su sociedad, de las diferencias en "limpieza de sangre"; su idea de justicia exige entonces el trato equitativo de esas diferencias, pero no incluye en él las disidencias en cuestiones religiosas o aún políticas, Los liberales del siglo XVIII extienden la equidad al respeto a las distintas opiniones y elecciones de vida, pero no consideran las diferencias en la asignación de oportunidades o en la distribución de bienes. Esa sería exigencia de los socialismos posteriores.

Podríamos pensar entonces que una idea general de justicia sería aquella que estableciera la equidad frente a todas las diferencias posibles y eliminara, por lo tanto, las desigualdades originadas en exclusiones. La teoría actual que más se aproxima a esta idea es, en mi opinión, la de John Rawls. Quisiera pues considerarla. Pero tal vez, al examinarla desde el punto de vista que nos ha ocupado hasta ahora, es decir, desde la experiencia de la exclusión en un contexto histórico, tendríamos que rectificarla.

La teoría de Rawls infiere los principios de justicia del razonamiento que haría cualquier sujeto en la llamada "posición original", si hiciera abstracción de todas las características que lo sitúan en una sociedad concreta. Ya mencioné las dificultades que suscita esa postura. Sin embargo, siguiendo nuestro enfoque que parte de la percepción de una injusticia, podemos considerar los principios que propone Rawls desde una perspectiva histórica: como resultado de la oposición a ciertas formas de exclusión vividas por una persona situada en una sociedad occidental desarrollada, en el siglo que termina.

Rawls formula dos principios de justicia. El primero se refiere a la libertad, el segundo a las desigualdades. Recordemos su texto:

"Primer principio: Cada persona ha de tener un derecho igual al sistema total más amplio de iguales libertades básicas, compatibles con un sistema similar de libertad para todos".

"Segundo principio: Las desigualdades sociales y económicas han de ser tratadas de manera que: a) sean para el mayor beneficio de los menos favorecidos... y b) estén adscritas a cargos y posiciones abiertos a todos, bajo condiciones de una equitativa igualdad de oportunidades".

A estos principios Rawls añade dos reglas. La primera establece la prioridad de la libertad sobre el trato a las desigualdades; la segunda decreta la prioridad de la justicia sobre la eficiencia. ${ }^{5}$

El primer principio establece, como valor superior de la justicia, el derecho de todos, por diferentes que sean, a las "libertades básicas". Estas abarcan las libertades de opinión y de conciencia, las de asociación, las libertades polí-

\footnotetext{
${ }^{5}$ A Theory of Justice, Harvard Univ. Press. Cambridge, Mass., 1971. p. 302.
} 
ticas, las de integridad de la persona y las protegidas por el orden jurídico. ${ }^{6}$ Son, en realidad, las que garantizan un ordenamiento constitucional conforme con la democracia moderna. Corresponden tanto a las llamadas "libertades negativas", que aseguran los derechos del individuo frente a la interferencia del poder del Estado, como a la "libertad positiva" que funda el derecho a la participación política conforme a las reglas de un sistema democrático. Según nuestro autor esas libertades corresponden a los individuos comprendidos como personas morales. ${ }^{7}$ Son las libertades necesarias para que una persona pueda elegir cómo obrar y seguir su concepción del bien en su vida personal y pública, dentro de los limites de la situación en que se encuentre y sin interferencia del poder del Estado. No comprenden, en cambio, las condiciones que harian posible la realización efectiva en la sociedad de sus elecciones de vida.

Rawls es consciente de que la "sociedad bien ordenada", en la que pueden aplicarse esos principios, debe tener dos características: una situación de "escasez moderada" y un "sentido de la justicia" plural, es decir capaz de admitir una multiplicidad de concepciones del bien. ${ }^{8}$ No puede aplicarse, por lo tanto, a sociedades con un nivel de escasez superior ni a las que se rijan por un criterio del bien uniforme, impuesto por el Estado o por el consenso social.

Desde nuestro punto de vista, podemos interpretar la teoría de Rawls como respuesta a una doble experiencia. La experiencia reciente de los totalitarismos en las sociedades occidentales ha conducido, en efecto, a la aversión general de tipo de exclusión: la de las diferencias en la elección de valores y fines que dirijan la vida individual. Por otra parte, el capitalismo salvaje suscitó un rechazo de las marcadas distinciones en el acceso a oportunidades políticas y sociales. Estas son las dos formas de exclusión que deberían suprimir los dos principios de Rawls. Pero en otras sociedades ¿no se presentan acaso otros tipos de exclusión que debieran considerar los principios de justicia? En la mayoría de los países no existen condiciones para que todos los ciudadanos puedan gozar de las "libertades básicas" enumeradas por Rawls.

Todo valor objetivo implica la posibilidad de satisfacer una necesidad real. La libertad es un valor objetivo porque se requiere para cumplir con la necesidad de dar sentido a nuestras vidas, eligiendo lo deseable para nosotros. Pero el ejercicio de esa elección precisa de condiciones mínimas. Para poder ser libre, ciertas necesidades elementales tienen que ser previamente satisfechas: son las de sobrevivencia (alimentación, habitación, vestido, seguridad de vida) y las de convivencia (pertenencia a una sociedad humana). En muchos países, amplios sectores son esclavos de esas necesidades elementales o, al menos, eștán sujetos en gran medida a ellas, al grado de impedirles seguir cualquier otro valor. La diferencia que los excluye de la libertad es su imposibilidad

\footnotetext{
${ }^{6}$ Liberalism 285.

${ }^{7}$ Op. Cit., p. 272-273.

${ }^{8}$ Op. Cit., p.81.
} 
de acceso a los bienes y servicios materiales mínimos, requeridos para sobrevivir como seres humanos independientes. En este caso, la justicia exige la atención prioritaria a aquellas necesidades vitales, dentro de los límites que la escasez impone a la sociedad.

En otros casos, las libertades básicas están consignadas en el orden jurídico e incluso forman parte de las prácticas de un sector de la población, pero otro sector, aunque goce formalmente de las mismas libertades, se encuentra en una situación de dependencia tal, que no puede obedecer a su propia voluntad y está obligado a plegarse a la ajena. Los sujetos de ese sector son libres según la ley pero carecen de libertad para decidir por sí mismos, por estar materialmente sujetos a otros hombres, por carecer de información sobre sus derechos o simplemente porque ejercerlos los coloca en el riesgo de perder su trabajo o incluso su vida. Esas situaciones no son la excepción en la mayoría del planeta; son las más frecuentes en los países del Tercer Mundo. En muchos de ellos, mientras un sector de la población participa de hecho en una asociación que garantiza - aunque sea ineficiente y parcialmente- las libertades, otro sector subsiste fuera de ese tipo de asociación, pues no está en condiciones de ejercer esas libertades. ${ }^{9}$

Podemos decir que, en esos casos, las libertades individuales "negativas" y las de participación política existen en el orden jurídico, pero no hay la posibilidad de realizarlas. Nadie es libre si carece de un tercer género de libertad: la de realización de lo que elige.

En algunas sociedades, se carece también de otra condición necesaria para el ejercicio de las libertades consignadas en el primer principio de Rawls. La realización de la libertad de elegir y de seguir esa elección no sólo requiere de la satisfacción de las necesidades de sobrevivencia, sino también de convivencia con otros hombres y mujeres semejantes en un ámbito cultural concreto. El individuo no puede elegir los valores que dan sentido a su vida ni determinar los fines últimos que la orientan más que dentro de las posibilidades que le ofrece la cultura a la que pertenece, por rudimentaria que ésta sea. Una sociedad es justa si respeta las diferencias de todos sus miembros en la elección de fines y valores. Pero esa elección supone la presencia ante la persona de un abanico de fines posibles y una jerarquía de valores que son comunes a una cultura. Las elecciones de vida de cada quien se dan bajo el supuesto de esas creencias básicas; pueden seguirlas o ponerlas en cuestión, pero no pueden menos de partir de ellas; son culturalmente dependientes. Cuando los miembros de una sociedad pertenecen a culturas distintas, el respeto de su capacidad de elección libre entraña el del sistema de creencias básicas, de valores y fines posibles, de la comunidad cultural a la que pertenecen. Dentro de un Estado multicultural - como el mexicano, el español o el canadiense- no puede darse por supuesto el acuerdo de fines y valores colectivos últimos entre personas

\footnotetext{
${ }^{9}$ Sobre este punto, véase mi libro El poder y el valor (Fundamentos de una ética política) Fondo de Cultura Económica, México, pp. 322-323.
} 
de culturas diferentes; por lo tanto, el presupuesto de cualquier acuerdo es el reconocimiento de esa diferencia. La falta de consignación en el orden jurídico del derecho a la autonomía cultural de los pueblos (o minorias) de culturas diferentes a la hegemónica, expresa un rechazo a la posibilidad de realización de ciertas libertades básicas, no considerado en el primer principio de Rawls. $\mathrm{Y}$ esa falta no es teórica; en muchos paises, miembros de culturas no hegemónicas hacen la experiencia personal de una exclusión distinta a las rechazadas por Rawls. La eliminación de esa exclusión corresponde a la satisfacción de una necesidad de pertenencia, que se añadiría a las necesidades de sobrevivencia como condiciones de posibilidad de la realización de las "libertades básicas". ${ }^{10}$

En los países en vías de desarrollo se dan experiencias continuas de exclusiones de un género distinto a las que dieron lugar al principio del respeto de las "libertades básicas" consignadas en. el principio de Rawls. A las "libertades negativas" y a las de participación política habría que anadir las libertades de realización. Estas exigen la satisfacción de necesidades elementales de sobrevivencia y de convivencia social.

El primer principio de Rawls debería ser precedido, por lo tanto, por otro que hiciera posible su aplicación a sociedades que no cumplen con ciertos requisitos de desarrollo económico y político y que experimentan otras formas de experiencia de la injusticia. Ese principio previo indicaría como prioridad de una sociedad justa la satisfacción de las necesidades de sobrevivencia y convivencia que hacen posible el ejercicio del derecho a las libertades básicas consignado en el primer principio.

Por otra parte ese añadido modificaría el alcance del primer principio. No podría suprimir el derecho de todos a las libertades mínimas que son propias de todo agente moral, como las libertades de conciencia y opinión y los derechos a la integridad de la persona, pero sí podrían regular el alcance de otras libertades, por ejemplo, las de participación política y las de acceso a los bienes de producción y distribución. El mismo Rawls parece aceptar esa posibilidad. "Es sólo cuando las condiciones sociales no permiten el establecimiento de esos derechos (a las libertades básicas) - escribe- que se puede conceder su limitación; y esas restricciones pueden ser acordadas sólo en la medida en que sean necesarias para preparar la vía a una sociedad libre" ${ }^{11}$ En Una Teoría de la Justicia, Rawls parece aceptar esa posibilidad de pasada y la presenta como una excepción a la regla, pero en su obra posterior es más claro. " $\mathrm{El}$ primer principio, que abarca los derechos y libertades iguales para todos, bien puede ir precedido de un principio que anteceda a su formulación, el cual exija que las necesidades básicas de los ciudadanos sean satisfechas, cuando menos en la medida en que su satisfacción es necesaria para que los ciudadanos entiendan y puedan ejercer fructíferamente esos dere-

\footnotetext{
${ }^{10}$ En Estado plural, pluralidad de culturas, Paidós, 1998, pp. 92-94 he desarrollado más ampliamente este punto.

${ }_{11}$ A Theory of Justice, Harvard Univ. Press, Cambridge, Mass., 1971, p. 152
} 
chos y esas libertades. Ciertamente tal principio precedente debe adoptarse al aplicar el primer principio". ${ }^{12}$

Estas reflexiones nos llevan a examinar el segundo principio de Rawls, el que versa sobre las desigualdades permitidas. Rawls parte de la consideración de una sociedad en que todos pueden ejercer, en principio, sus libertades básicas. En una sociedad tal, no se pone en duda la justicia de una distribución equitativa de bienes y servicios. En efecto, segun Rawls, son "permisibles" las concepciones plurales acerca del bien común si aceptan que la equidad implica una distribución igualitaria de "bienes primarios" . Estos "bienes" comprenderian no sólo las "libertades básicas" de que trata el primer principio, sino también "puestos y cargos" y "riqueza" ${ }^{13}$ Lo que hay que justificar, por lo tanto, es la desviación de esa distribución equitativa. Esta sólo podría aceptarse en la medida en que contribuya al bien general, desde la perspectiva de los menos favorecidos.

Permítaseme citar, al respecto, un párrafo de un trabajo mío anterior. "En la fórmula de Rawls las desigualdades se justifican si redundan en beneficio de todos. Permitirlas puede traer un incremento en los bienes de la sociedad y, por lo tanto, en las posibilidades de una mayor libertad de realización para todos. En efecto, para obtener una mayor productividad, en una sociedad de escasez de recursos, y aumentar así el caudal de bienes disponibles, parece necesario admitir una desigualdad limitada, que conceda mayores ventajas a quienes tienen mayores capacidades de producir para el mercado. Habría que interpretar entonces el segundo principio de Rawls de modo de justificar las desigualdades si y sólo si son necesarias para lograr mayores posibilidades de realización para todos. Si hubiera otros medios para obtener el mismo resultado, serían injustificables. Esto implica que, para admitir una desigualdad, se requiere demostrar que su consecuencia necesaria y previsible es un aumento en los bienes susceptibles de una distribución equitativa. Las desigualdades que tenemos que aceptar son las que ayuden a vencer la escasez y lograr mayor prosperidad. Por lo tanto, sólo son admisibles en la medida en que produzcan esa consecuencia. La demostración corresponde a quien se beneficie de una desigualdad. Cualquier desigualdad en oportunidades y recursos que no pueda aducir esa demostración es injusta".

"Pero el beneficio que pudiera justificar una desigualdad no puede medirse por el aumento total de los bienes de la sociedad, pues éste podría incrementarse sin redundar en una mejora en las libertades de realización para todos. Lo que las justifica es su contribución a esa mejora y ésta se mide por el aumento de los bienes de que pueden disponer quienes aún padecen una carencia de oportunidades y recursos. Por eso Rawls entiende que el beneficio obtenido por una desigualdad económica o social debe ser juzgado desde el punto de

\footnotetext{
${ }^{12}$ Liberalismo político, Fondo de Cultura Económica, México, p. 32

${ }^{13}$ Op. Cit., p. 177; cfr. también pp. 90 y 286.
} 
vista de los menos favorecidos. En efecto, sólo si ellos mejoran, mejorará el sistema general de equidad". ${ }^{14}$

El punto más discutible de la propuesta de Rawls es el de la prioridad del principio de libertad sobre el que regula las desigualdades. Según esta regla prioritaria, ninguna política de restricción de las libertades básicas, señaladas en el primer principio, estaría justificada en favor de una mejor distribución en los bienes. La igualdad social y económica queda así restringida al respeto a las "libertades básicas". Esta restricción recoge la experiencia de los atentados a las libertades individuales perpetrados en nuestro siglo por ideologías que pretendían justificarlos en la disminución de las desigualdades. Responde a una percepción histórica de una injusticia específica. Sin embargo, en sociedades en que la experiencia fundamental de la injusticia es la exclusión debida a las desigualdades económicas y sociales de un amplio sector de la población, aquella restricción es, por lo menos, discutible.

La regla rawlsiana de que el derecho igual de todos a las libertades básicas es prioritario a cualquier acción contra las desigualdades existentes, podría entenderse en el sentido de la existencia de un derecho general a la libertad, independiente de cualquier derecho a la igualdad. Me parece que este punto no resiste el análisis.

Ronald Dworkin es convincente al sostener que no hay un derecho general a la libertad, sino sólo derechos a libertades específicas. Por otra parte, el derecho a libertades específicas no puede oponerse a un derecho a la igualdad; antes bien el derecho a la libertad deriva de un derecho más fundamental a la igualdad, entendida como equidad de trato a las diferencias. "Los derechos individuales a diferentes libertades sólo deben ser reconocidos cuando se puede demostrar que el derecho fundamental a ser tratado como igual los exige. Si esto es correcto, entonces el derecho a diferentes libertades no entra en conflicto con ningún supuesto derecho concurrente a la igualdad, sino que, por el contrario, se sigue de una concepción de la igualdad reconocidamente más fundamental". ${ }^{15}$

En mi opinión, entre las diferentes libertades posibles, hay que circunscribir las libertades mínimas que constituyen a uh hombre y a una mujer como sujetos morales, es decir como agentes con la posibilidad de obrar o no obrar siguiendo su propia voluntad, dentro de los límites de su situación. Son las libertades de conciencia, de expresión, de integridad de la persona, de decisión en el ámbito privado, a las que habría que añadir las condiciones que he señalado antes: de sobrevivencia y de convivencia social, que permiten su realización. Violar esas libertades en alguna persona implica su exclusión de la comunidad de sujetos morales. Su vigencia se funda, pues, en el igual derecho a la no exclusión.

\footnotetext{
${ }^{14}$ El poder y el valor (Fundamentos de una ética política), Fondo de Cultura Económica, México pp. 319-320.

${ }_{15}^{15}$ Los derechos en serio, Planeta-Agostini, Barcelona, 1993, p. 390.
} 
Pero no están en el mismo caso otras libertades específicas, desde la libertad a una participación política hasta las libertades de tránsito, pasando por las de propiedad y disfrute de bienes privados. Por supuesto que una sociedad justa debe tratar de propiciar esas libertades para todos por igual. Esto quiere decir que no son independientes de la situación de desigualdad existente, ni prioritarios respecto a la equidad de trato. Por eso, en el caso de una situación de injusticia, el trato igual para todos puede exigir la reducción de esas libertades en un sector, con el objeto de que todos sean libres. El propio Rawls, en su trabajo posterior a Una Teoria de la Justicia, llega a reconocer que la prioridad de la libertad sólo es válida cuando existen "condiciones razonablemente favorables" para permitir su ejercicio. ${ }^{16}$ Pese a esa observación, no elimina de su concepción de la justicia la regla de prioridad citada.

Creo que podemos concluir que, cuando no todos los miembros de una sociedad gozan de las posibilidades reales de ejercer sus libertades, un principio de justicia obligaría a restringir ciertas libertades específicas de los demás miembros, con las siguientes limitaciones:

1) La restricción no puede afectar a las libertades mínimas que requiere todo sujeto moral y son condiciones de la dignidad de la persona.

2) La reducción de las demás libertades puede efectuarse en la medida en que tenga por efecto que quienes carecen de las libertades mínimas accedan a ellas.

3) La reducción de las libertades sólo puede durar el lapso necesario para remediar la carencia de libertad de los excluidos. Ese lapso puede ser relativamente breve en situaciones excepcionales de emergencia, por ejemplo, por causa de guerra, hambruna o catástrofes naturales. En situaciones de penuria permanente, en cambio, podría durar hasta lograr un avance material en la mayoría de la población, suficiente para liberarla de su esclavitud a sus necesidades elementales y de su sujeción a una voluntad ajena.

\section{III}

Los principios de justicia de Rawls se aplican a una sociedad estática intemporal, porque expresan lo que juzgarian sujetos racionales que se suponen semejantes en cualquier situación histórica. La alternativa contraria que he propuesto es asumir el punto de vista de quienes experimentan la injusticia como exclusión, para llegar a una idea cada vez más amplia de justicia. Desde esa perspectiva, la idea de justicia se presenta como la eliminación de las exclusiones existentes en cada caso y el trato igual a las diferencias. La sociedad justa se figura como una situación proyectada, por alcanzar, desde la situación existente. No puede corresponder a ningún consenso real, pero tampoco se deduce de lo que eligirían sujetos que no pertenecieran a una sociedad injusta. La justicia

${ }^{16}$ Op. Cit., p. 276. 
es, en cada caso concreto, lo "otro" de las exclusiones percibidas. Sólo podremos acercarnos a ella con la transformación de la sociedad tal como existe en ese caso.

Dado que las características diferenciales excluidas varian en distintas circunstancias históricas, si queremos formular principios generales de justicia, éstos deben ser tales que puedan aplicarse a circunstancias variables. Por otra parte, deben tomar en cuenta las desigualdades causadas por exclusiones precedentes no rectificadas. La exigencia de la abolición de las injusticias existentes en cada caso implica también la disminución progresiva de las desigualdades ocasionadas por exclusiones históricas anteriores.

Resumamos. Podríamos formular en cuatro puntos las notas que corresponderían a una concepción general de la justicia que obedeciera al punto de vista anterior.

1) Todas las personas tienen igual derecho a los valores básicos de sobrevivencia y convivencia, como condiciones para fungir como sujetos morales. Deben eliminarse, en consecuencia, en cada situación histórica, las exclusiones que lo impidan.

2) Todas las personas tienen igual derecho al sistema total más amplio de las libertades mínimas requeridas para que un sujeto pueda fungir como agente moral.

3) Las demás libertades solo pueden restringiese en la medida en que esa restricción sea necesaria para cumplir los dos puntos anteriores.

4) Las desigualdades políticas, sociales y económicas deben ser tratadas de manera que: a) sean para el mayor beneficio de los menos favorecidos; y b) las desigualdades producidas por exclusiones históricas anteriores puedan ser rectificadas mediante la adscripción de cargos, posiciones y oportunidades que compensen a los anteriormente excluidos, hasta lograr la igualdad en su adscripción.

El punto (1) expresa el principio que -según argumenté- debe preceder al Primer Principio de Rawls, para poder aplicarse a cualquier sociedad.

Los puntos (2) y (3) reproducen el Primer Principio de Rawls con las modificaciones que discutí anteriormente.

El punto (4) corresponde al Segundo Principio de Rawls, con una modificación en el inciso (b) que señala el tratamiento de las desigualdades de origen histórico, mediante la posibilidad de una "acción positiva" que las elimine progresivamente.

Esta propuesta teórica pretende traducir una idea de la justicia como equidad de trato de todas las diferencias. ¿Corresponde a una concepción particular del bien común?

En una sociedad plural coexisten muchas concepciones diferentes del bien. Los individuos tanto como los grupos sociales conceden prioridades distintas de valores colectivos. El consenso social varía: para unos es el orden el supremo valor común, para otros, la libertad, o la prosperidad, o la gloria, o el honor... 
A las distintas concepciones del bien común corresponden sendos proyectos sociales y políticos. Cuando la sociedad hace de lado esa multiplicidad y llega a un consenso en una sola concepción del bien, cae de manera inevitable en la exclusión de todos aquellos que no comparten esa concepción. Por lo tanto, si la justicia consiste en la no- exclusión, entonces no puede imponer una concepción del bien común.

El problema puede expresarse en la pregunta que plantea Rawls: “ ¿ Cómo es posible la justicia en una sociedad en la que coexisten una pluralidad de concepciones del bien?" ${ }^{17} \mathrm{El}$ concepto de justicia no puede estar ligado a una concepción específica del bien que pueda oponerse a otras.

De alli algunos concluyen una concepción de la justicia que podría resumirse en dos proposiciones: 1) La justicia no es un bien. Habria que distinguir entre dos conceptos: lo bueno (good) y lo justo (right). 2) Por consiguiente, todo Estado justo es neutral frente a cualquier idea de lo bueno; no persigue ningún bien común.

Pero esta concepción es discutible. Habría que aclarar, en mi opinión, un par de puntos.

En primer lugar, las concepciones distintas del bien, en la medida en que se oponen entre sí, responden a intereses particulares de individuos o grupos. Su valor es pues relativo a ellos; no son generalizables. El bien deseado no es, en realidad, común, sino relativo a ciertos sujetos. La justicia, en cambio, es un valor objetivo; porque es válida para cualquier sujeto, cualquiera que sea su concepción del bien. Es pues un valor de segundo nivel. La equidad de trato es un valor formal, que se aplica a cualquier sujeto con una concepción sustantivo, particular, del bien. Pero no por ser formal deja de ser objetivo. Luego, es el único valor social común, aplicable a todas las elecciones particulares de bienes, puesto que no se identifica con ningún bien particular y no responde al interés de un individuo o grupo, sino a un interés general.

Desde esa perspectiva, la exigencia de justicia otorga al Estado una función que rebasa su carácter pretendidamente "neutral". Tiene por misión proponer un fin común a todos los miembros de la sociedad, guardando sus diferencias. Un Estado conforme a la justicia tendría por tarea primordial la disminución y aún la eliminación, en lo posible, de toda situación de exclusión, actual o pasada, que impida alcanzar la realización de la libertad para todos. Mientras las políticas basadas en un modelo liberal tradicional de la sociedad no se comprometen con ninguna diferencia, tolerando por igual todas sus formas, una política igualitaria buscaría alcanzar la igualdad en las diferencias, asumiendo ese fin como justificación de un tratamiento preferente a los sectores que sufren una exclusión total o parcial. Se justificaría así una discriminación positiva o "acción afirmativa", en favor de las personas y grupos sociales víctimas de desigualdades, como medio para alcanzar la equidad.

Concluyamos con algunas observaciones:

${ }^{17}$ Op. Cit., p. 323-324. 
La idea de justicia comprende el trato igual a todas las concepciones sobre el bien, pero también propone un bien común de segundo nivel, que se desprende justamente del trato equitativo a las diferentes elecciones de vida. La justicia aparece entonces como un bien superior a la pluralidad de bienes que cada quien elige libremente. Sobre los ideales de imparcialidad y tolerancia frente a todas las diferencias, se levantan las metas de cooperación y solidaridad entre los diferentes, para alcanzar el bien común de la justicia.

A la idea de una asociación política constituida por ciudadanos diferentes pero iguales sólo ante la ley, se substituye la de una comunidad de hombres y mujeres que hacen suya la construcción de un valor común. A la tolerancia como virtud de una sociedad neutral ante las diferencias existentes, sucede la cooperación para lograr un fin común: la abolición de toda exclusión que impida la libre realización de todas las diferencias.

\section{EXCLUSIÓN Y CIUDADANÍA}

\section{I}

En las dos conferencias anteriores traté de mostrar cómo distintas nociones de justicia están en relación con experiencias correspondientes de exclusión. Me parece que un concepto en el que podría verse con claridad esa relación es en el de ciudadanía. Hemos evocado las exclusiones de personas y grupos con características diferenciales respecto de comunidades de consenso social; con el concepto de ciudadanía nos introducimos a la exclusión respecto del pacto político.

"Ciudadanía" es un concepto histórico. No corresponde a todo Estado, puesto que los hay con súbditos y no con ciudadanos, sino a un género de Estados que se fincan en una forma determinada de asociación política. Podemos encontrar un remoto antecedente en la constitución de Atenas a partir de la reforma de Clístenes.

Con la idea de ciudadanía se pasa de la pertenencia al clan, a la tribu o a la comunidad étnica, a la pertenencia a la ciudad-Estado. Se establece un nuevo tipo de liga comunitaria y de vínculo de autoridad. Ya no se basan en el parentesco o en el servicio recíproco; tampoco en el carisma; el ciudadano está ligado a su ciudad por un enlace impersonal: la ley. Para él la cooperación en un propósito social común ya no se finca en la comunidad de cultura o en el linaje, sino en un contrato entre individuos: no puede invocar, por lo tanto, una lealtad personal sino una obligación. Desde sus antiguos orígenes, la ciudadanía guarda dos características: 1) La homogeneización de todos los individuos por poseer una cualidad común: todos están sometidos al mismo orden expresado en una única legislación. Poco importan, para la ciudadanía, las diferencias entre comunidades y linajes distintos; nadie puede alegar, por 
lo tanto, derechos diferenciados. 2) La obligación de todos los individuos hacia el mismo poder impersonal: el Estado.

El imperio romano supo aprovechar este doble carácter de la ciudadanía. Ante la diversidad de naciones y culturas, el imperio establecía la homogeneidad del poder político. El ciudadano romano, sin dejar a menudo de pertenecer a una nacionalidad bárbara, simbolizaba el poder único de Roma. La ciudadanía se utilizaba también como gaje de la fidelidad al poder imperial. El Estado podía reclamarle obediencia, aún si entraba en conflicto con la lealtad a su comunidad. La ciudadanía tiene una función ambivalente: libera al ciudadano de su dependencia exclusiva a las autoridades locales, a sus usos y costumbres, y obtiene la protección del Estado imperial, al mismo tiempo, se deslíen sus vínculos con la comunidad a que pertenece y se debilita la seguridad de su propia identidad.

En la Edad Media la ciudadanía no tiene una función que cumplir en el seno de comunidades y estamentos que conservan todas su diferencias sociales, culturales y aún legales. En cambio, desempeña un papel importante en las ciudades. El ciudadano es el burgués, que se rige por las reglas de la ciudad y no por la fidelidad a un señor o por la lealtad a su comunidad local. Lleva en sí el germen de un factor de liberación frente al orden jerárquico del feudalismo. Las ciudades obtienen fueros y privilegios, establecen obligaciones que igualan a sus miembros y los emancipan de su sumisión a instancias personales de poder.

El concepto moderno de ciudadanía convierte las dos características señaladas en elementos constitutivos del Estado- nación. El Estado- nación es un concepto nuevo, de invención reciente. Supone la unificación de un poder político (Estado) con una comunidad de cultura sometida a un proyecto común (Nación). Se inicia ya con la consolidación de la monarquía en varios Estados europeos, en Francia, España, Inglaterra; pero sólo adquiere identidad definitiva con las revoluciones democráticas y de independencia de los siglos XVIII y XIX. Entonces se realiza la unificación del poder político con la construcción de una sola patria. "A todo Estado debe corresponder una nación, a toda nación, un Estado" : es el lema tácito de los modernos nacionalismos ${ }^{18}$.

El Estado- nación es una organización política nueva con dos rasgos diferenciales: En el interior, establece una unidad de control político y administrativo y un ordenamiento legal sobre la diversidad de pueblos y poderes locales. Su función es estatuir homogeneidad en lo diverso. Hacia el exterior, reivindica una soberanía irrestricta; rechaza cualquier intromisión de un poder extranjero: unidad interior cercada por altas fronteras inviolables.

El Estado- nación surgido de las revoluciones democráticas es el dominio del "pueblo". ¿Pero cómo reconocer al pueblo? No puede ser ya el conjunto abigarrado de organizaciones y estamentos que constituyen la sociedad real,

\footnotetext{
${ }^{18}$ Véase E. Gellner, Naciones y nacionalismo. Madrid, Alianza, 1988. p. 13.
} 
ahora debe ser una suma de individuos que compartan por igual ciertas características en relación con el Estado-nación: frente a él, tienen los mismos derechos y las mismas obligaciones; por eso, forman parte del "pueblo" quienes, ante las maquinaciones de los partidarios del antiguo régimen" tienen la responsabilidad de defender a la "patria" unificada. Ciudadano es el sujeto del contrato político que da origen a la nueva nación y el encargado de protegerla contra los enemigos exteriores. Todos los individuos, en cuanto comparten esa función, se igualan entre sí. No importa ya, por lo tanto, su integración en distintas comunidades, culturas o estratos sociales. La patria común unifica a todos frente a los extraños. La ciudadanía nacional es el sello de esa unificación. "Estado-nación" y "ciudadanía" nacen juntos. "Ciudadano" es el sujeto de una asociación política, organizada como Estado, que le otorga derechos; "Estado" es una asociación constituida por el contrato realizado por el conjunto de ciudadanos. El ciudadano inaugura una nueva pertenencia.

Expresa un doble movimiento: la eliminación de exclusiones sociales anteriores y el establecimiento de otra exclusión de un nuevo género.

Por una parte, al igualar en derechos a individuos de diversos estratos sociales, elimina la exclusión política que sufrian quienes no pertenecían a las clases altas, la aristocracia y el clero. El ciudadano común se levanta contra los privilegios de rango y de clase. La ley no hace acepción de personas, establece la igualdad que las adhesiones personales diversificaban.

Sin embargo, origina una nueva exclusión. El Estado se reserva otorgar la ciudadanía a quienes tengan ciertas notas y no otras. Durante mucho tiempo es excluida la mitad de las personas, las mujeres. Recordemos los comienzos de la ciudadanía. A la Declaración de derechos de 1789 Olympe de Gouge tiene que oponer Los derechos de la mujer y de la ciudadana donde se encuentra la conocida frase: "La mujer tiene el derecho de subir al cadalso; debe de tener igualmente el derecho de acceder a la tribuna". Durante gran parte de la historia de los Estados nacionales, la ciudadanía es negada no sólo a las mujeres, sino también a los desposeídos; a menudo el Estado divide a los ciudadanos en "activos" y "pasivos" y establece toda clase de limitaciones y obstáculos para obtener la ciudadanía. Aún ahora, después de muchos años de luchas cívicas, los derechos de ciudadanía les son negados a muchos hombres y mujeres, miembros de la sociedad, en principio libres e iguales: por ejemplo, los inmigrantes, los residentes extranjeros, los apátridas, los nómadas.

Al establecer una medida uniforme para todo individuo, la ciudadanía no reconoce adhesiones a comunidades o nacionalidades diferenciadas; si no excluye del todo, al menos limita y margina a las pertenencias comunitarias. Evoquemos un ejemplo histórico. En las antiguas colonias españolas de América, los pueblos indígenas mantuvieron gran parte de sus formas de vida, sus usos y costumbres, y aún algunas de sus organizaciones sociales y políticas, aunque adaptadas a las nuevas influencias culturales. Las Leyes de Indias les concedían un estatuto jurídico en gran medida diferente al de los pueblos criollos y mes- 
tizos; a la vez que los apartaba del resto de la sociedad, les otorgaba una autonomía limitada. Los Estados nacionales constituidos después de la independencia no admitieron esas divergencias. Todos debían estar sujetos a las mismas reglas. Por mor de la igualdad, se suprimían las "castas" y todas las diferencias debidas a la raza o a la pertenencia étnica. Ya no había privilegio alguno para la mayor "limpieza de sangre", pero tampoco protección especial para quienes carecían de ella. Todos eran "ciudadanos americanos" y nada debía distinguir a un indio de un mestizo o de un español. Al mismo tiempo se borraban esas desigualdades junto con los rasgos distintivos que mantenían la identidad de los pueblos indígenas. Más tarde, las repúblicas liberales, siguiendo su concepción individualista, asestaron un golpe mortal a las comunidades; a nombre de los derechos individuales de propiedad, intentaron suprimir la propiedad comunal en la que se sustentan tradicionales valores comunitarios.

La política liberal tiene otro rostro: la unidad de la nación exige una cultura unitaria. El Estado debe, en realidad, crear una nación unida donde reinaba antes la diversidad, y el arma principal para construirla es la educación, tanto en la escuela como fuera de ella. Por eso tiene que propiciar, desde el poder público, la formación de una cultura que preste identidad a la nueva nación. El nacionalismo cultural es un rasgo indispensable de una política estatal que busca homogeneizar las diferencias comunitarias en una formación común a todo buen ciudadano. La unidad de cultura y la ciudadanía se complementan. Ambas son la marca que el poder del Estado-nación imprime en el individuo. La primera propicia unidad en el campo social, la segunda, en el campo político. La participación en una sola cultura nacional procura que los distintos pueblos, con raices distintas, se fundan en un sistema nacional homogéneo. La ciudadanía única proclama que todo poder de las comunidades e instituciones diversas, que podrían mediar entre el individuo y el Estado, debe inclinarse ante los designios de un poder unitario superior.

II

Los derechos de ciudadanía forman parte del orden normativo estatuido por el Estado. Pertenecen a la legislación positiva y cambian con ésta. Son pues posteriores a la constitución política. En cada caso son acordados por el poder existente. Están pues condicionados históricamente por un sistema de poder determinado; responden a su voluntad en cada caso. De allí que los derechos del ciudadano no coincidan necesariamente con los derechos humanos, los cuales expresan exigencias inherentes a toda persona moral, independientemente del sistema político al que esté sujeta. Los derechos humanos se justifican en la necesidad de reconocimiento, por parte del Estado, de valores básicos propios de toda persona humana; preceden, por lo tanto, a la constitución del orden jurídico estatal. (La "precedencia" de esos valores - fundamento de 
los derechos humanos- respecto de los derechos del ciudadano no debe entenderse, naturalmente, en un sentido temporal sino de justificación de validez).

Desde la Revolución Francesa se planteó el problema de distinguir entre dos géneros de derechos: los "derechos del hombre" y los "del ciudadano". La distinción aparece en el título mismo de la Declaración de 1789. Pocos legisladores, sin embargo, definieron claramente su diferencia. Uno de ellos fue el ciudadano Thoret quien distinguió entre "derechos absolutos" y "derechos condicionados". "Los derechos absolutos -declaraba ante la Asamblea- son aquellos de tal manera inherentes a la naturaleza del hombre que son inseparables de él y le siguen en todas las circunstancias y posiciones en que se encuentra. Los derechos condicionados son los que suponen cierto Estado o cierta institución que depende o ha dependido de la voluntad. Tales son los que se originan en la propiedad o en las convenciones, o los que tienen por fundamento las constituciones o reglamentos de la asociación...." ${ }^{19}$

Los "derechos absolutos" pertenecen a todo sujeto moral. Que se funden en la " naturaleza del hombre" corresponde a la interpretación del naturalismo jurídico propio de la época, el cual remitía a la hipótesis de un derecho natural. Pero si queremos prescindir de esa concepción metafísica, podríamos simplemente hablar de valores propios de toda persona moral que dan lugar a una exigencia ética: no admitir impedimento que los coharte y, por lo tanto, ser protegidos en la asociación política. Su protección implica su inclusión por parte del Estado, en el orden jurídico que promulgue. Entonces los valores morales, inherentes a toda persona humana, dan lugar a "derechos".

La identidad de la persona moral comprende la libertad de elegir los valores y fines necesarios para regir su vida. Valores propios de todo sujeto moral son los que permiten su realización como persona con una identidad propia. Los valores inherentes a la persona no son producto del orden jurídico positivo. Por el contrario, su reconocimiento y respeto son condiciones para que el orden jurídico responda a las exigencias de una comunidad de sujetos morales. A diferencia de los derechos del ciudadano, el Estado no otorga los derechos humanos, no hace más que reconocer públicamente los valores que constituyen a toda persona moral. Por ese reconocimiento les concede normatividad positiva.

Aún sin aceptar el carácter "natural" de los derechos humanos, subsiste una diferencia tajante entre éstos y los derechos del ciudadano. Los primeros se fundan en valores cuya realización el Estado debe garantizar si pretende respetar un orden moral; los segundos, son producto de la voluntad de cada Estado. Los primeros son comunes a cualquier asociación que respete los valores básicos de las personas; los segundos son particulares a cada constitución política, condicionada históricamente. Aquellos sólo pueden ser reconocidos por el legislador, éstos deben ser acordados. La vigencia de los derechos humanos en una asociación señala la pertenencia de sus miembros a la comunidad uni-

\footnotetext{
${ }^{19}$ Cit. En E. Jouve, Le droit des peuples, Paris, P.U.F., 1986, p. 146.
} 
versal de las personas morales; la vigencia de los derechos del ciudadano marca la pertenencia a una asociación política determinada.

La cuestión es entonces la de los criterios para acordar o no la ciudadanía. Estos no se deducen de la concepción que tengamos sobre los derechos humanos, sino de los fines políticos de cada Estado. La definición de "ciudadanía", inscrita generalmente en las constituciones, depende del tipo de asociación política que se proyecte. Pero, en todo caso, la ciudadanía queda definida, no por los derechos que se reconozcan al individuo por ser persona humana, sino por la participación política que se le conceda. Este rasgo definitorio de ciudadanía permanece en distintas concepciones filosóficas de las más alejadas épocas históricas. Aristóteles definía al ciudadano como "el que tiene la facultad de participar en el poder deliberativo o judicial" ${ }^{20}$ Siglos más tarde, Rousseau entendía por ciudadano "el que participa en la autoridad soberana" ${ }^{21}$ y para Kant se llaman ciudadanos "los miembros de una sociedad civil, es decir de un Estado, reunidos para legislar". "Sólo la capacidad de votar - advierte- define la calificación de ciudadano" y ésta se encuentra restringida por las reglas políticas que establece el Estado ${ }^{22}$. La ciudadanía se ha medido siempre por la participación de ciertos sujetos - que no coinciden necesariamente con todos los sujetos morales- en el poder político.

La ciudadanía establece así una demarcación entre la comunidad posible de sujetos morales y el conjunto de sujetos políticos a los que el Estado concede iguales derechos; implica, por consiguiente, la exclusión de la asociación política de todas las personas que no posean las características que el Estado establece como definitorias del sujeto político.

Estamos ante una nueva forma de exclusión, de un tipo particular, porque disfrazada de un respeto a la igualdad. La dificultad de hacerla consciente estriba en su ambivalencia. Porque la ciudadanía presenta un aspecto liberador. Se invoca frente a los privilegios de clase; proclama la igualdad de todos los miembros de la sociedad ante el Estado. Por eso tantos teóricos liberales pueden cantar sus virtudes; por eso pueden reivindicar la ciudadanía como parte del poder del pueblo frente a los intereses particulares de grupos. Pero su cara emancipadora puede ocultar otra excluyente, que sólo pueden experimentar quienes la padecen. Su función excluyente presenta dos formas principales que corresponden a los dos aspectos que señalé del Estado- nación. En el interior del país, el Estado nacional está vocado a establecer la homogeneidad; puesto que la ciudadanía es su instrumento, tenderá a excluir de ella las características que rompan esa uniformidad. En las nuevas naciones que surgen de antiguas situaciones coloniales, la ciudadanía común intentará borrar las diferencias de las distintas comunidades y pueblos que las constituyen. Hacia el exterior, la ciudadanía se verá como una protección contra el extranjero;

\footnotetext{
${ }^{20}$ Política, III, $1275 \mathrm{~b}, 15$.

21 Du Contrat Social, I, 6.

${ }^{22}$ Metafísica de las Costumbres, “Doctrina del derecho”, II, S, 46, 314, 30.
} 
tenderá entonces a limitar los derechos de inmigrantes y residentes foráneos; los mantendrá al margen de la vida ciudadana.

Ambos tipos de exclusión son inherentes a la concepción del Estado-nación moderno. Una injusticia de nuevo tipo está ligada a la división en entidades estatales soberanas que intentan afianzar su poder en la unidad interior. Quizás dentro de un par de siglos se asistirá a la desaparición de los Estados nacionales y a la constitución de formas de gobierno mundiales sobre un conjunto de nacionalidades, etnias y comunidades diferentes, confederadas en organizaciones políticas y económicas regionales. Tal vez entonces parezca extraña la división del planeta en entidades que reivindican soberanía irrestricta. Una ciudadanía universal, con especificaciones locales variadas, correspondería mejor a esa situación futura.

Pero esa meta es aún lejana. Antes de llegar a ella se impone un largo periodo de transición, en el que subsistirá el Estado-nación. La abolición de las soberanías nacionales no llevaría, en estos momentos, a un gobierno mundial equitativo sino a la consolidación del nuevo poder económico del capital financiero y de las grandes empresas transnacionales. Una soberanía nacional compartida con varias naciones, para solucionar problemas comunes, cumple aún una función imprescindible: preservar el control de los países sobre sus recursos, sin tener que someterlos a un poder económico mundial libre de toda regulación. Por otra parte, la persistencia de la unidad de un Estado-nación, que reconozca la diversidad de los elementos que componen el país, es, aún indispensable para evitar el conflicto que podría desatarse entre las diferentes etnias o nacionalidades que lo componen. En el tema que nos ocupa, el Estado de transición debería hacer compatible por un largo periodo la ciudadanía nacional con el reconocimiento de la pluralidad de pertenencias de las personas que componen la sociedad. ¿Cómo sería posible la ciudadanía, ya no en un Estado-nación homogéneo, sino en un Estado plural?

Examinaremos ese punto en relación a las dos formas de exclusión que hemos mencionado: 1) La exclusión de las comunidades diferenciadas dentro de la nación; 2) La exclusión de los extranjeros residentes.

\section{III}

La mayoría de los antiguos países colonizados por Occidente accedieron a la constitución de un Estado nacional después de su independencia. Es sólo entonces cuando, con la noción de un Estado-nación homogéneo se adoptó el concepto complementario de una ciudadanía igual para todas las personas cuyas identidades reales estaban ligadas a su integración en etnias y comunidades concretas. Pero la lucha por mantener esas identidades perduró, bajo la aparente unificación de la ciudadanía común. Hoy vuelve a manifestarse en la demanda de autonomías regionales, étnicas o nacionales. Entre los conceptos de ciudadanía nacional y de autonomía parece abrirse entonces una contradicción. 
El ciudadano es, por definición, sujeto de derechos iguales para todo individuo, cualesquiera que sean sus diferencias culturales o sociales; la autonomía, en cambio, establece la adscripción de sujetos a comunidades con ciertos derechos diferenciados. Se plantearía así un aparente dilema: conservar el concepto tradicional de ciudadanía a riesgo de socavar las pretensiones de autonomía de los pueblos o mantener derechos autónomos de los pueblos con el riesgo de diferenciar el concepto de ciudadanía.

La primera opción sería fiel a la concepción liberal y republicana de un Estado nacional homogéneo; la idea de ciudadanía iguala ante la ley a todos los miembros de un Estado; es opuesta, por principio, a la vigencia de derechos diferenciados. Sin embargo, puesto que a todos concede la misma libertad, tendría que respetar las diferencias que derivan de su ejercicio. Nada debería oponerse en el orden legal a que cada quien mantenga y desarrolle sus formas de vida, por diferentes que sean, con tal de no interferir en la libertad de los demás. En esta concepción, los derechos a las distintas formas de vida, de culturas diferenciadas, son asimilados a los derechos privados, como los de profesar una religión, sostener y expresar ciertas creencias o asociarse con fines legitimos. Los derechos civiles, comunes a una ciudadanía única, bastarían según esta concepción para satisfacer las demandas de respeto a las diferencias. No sería necesario, por lo tanto, conceder derechos de autonomía.

Esta postura teórica no es, sin embargo, convincente. Podría ser aceptable sobre el supuesto de un Estado en el que todos los pueblos que lo componen gozaran, de hecho, de las mismas oportunidades para ejercer sus derechos. Pero la realidad es otra. Los Estados nacionales fueron el resultado de la imposición de un pueblo sobre otros y guardan aún ese carácter. Los derechos del ciudadano son, como mencioné, posteriores a la constitución del Estado nacional y fueron promulgados por él. Por ello, tanto los lineamientos del nuevo Estado como los rasgos de la ciudadanía respondieron a la concepción del pueblo dominante y no siempre nacieron con el consenso de los dominados. Por esta razón, a menudo se confunden los derechos propios de cualquier persona sujeta al poder político de una asociación con la manera de interpretar esos derechos y de expresarles según las concepciones del pueblo dominante. En la realidad, tanto social como jurídica, se confunden las notas de una ciudadanía que deberian ser propias de todo sujeto del Estado con las que corresponden al miembro de una nacionalidad particular. La igualdad en la participación política, que establece una ciudadanía compartida, se confunde con la homogeneidad en el campo social y cultural, por pertenecer a una nación.

Desde la Revolución Francesa, el "ciudadano", a la vez que es un sujeto de derechos políticos, es también la encarnación del miembro de la nueva nación unificada. El ciudadano es el encargado de defender la nación francesa contra los extranjeros, con los cuales se alían los aristócratas, el clero y los funcionarios reales. La confusión entre ciudadanía y nacionalidad queda consagrada desde entonces, en todas las nuevas naciones, como un prejuicio que 
no se somete a discusión. Es aceptado incluso por destacados autores. A modo de ejemplo, citaré un texto clásico. "La ciudadanía o nacionalidad -leo- es un estatuto personal cuya adquisión y pérdida son regidas a la vez por el derecho del Estado y el derecho internacional". El autor de esta frase es nada menos que Hans Kelsen. ${ }^{23}$ "Nacionalidad" se emplea como un concepto equivalente a "ciudadanía" ; no tiene una connotación cultural e histórica sino jurídica y política; igual que la ciudadanía, depende de la voluntad del Estadonación. Esta confusión es aún más patente en el caso de países que comprenden culturas de origen distinto al occidental que, por lo tanto, no incluyen el concepto de ciudadanía moderna tal como se estableció en Occidente.

Desde esa perspectiva, la igualdad política se revela con el sello de una visión de la ciudadanía propia de una corriente filosófica particular, la que prevaleció en un momento de la historia de Occidente. Por ejemplo, entre los derechos del ciudadano, ocupan un lugar prominente las garantías de su libertad privada frente al poder del Estado, pero no tienen la misma importancia las obligaciones de servicio a la comunidad; su visión es individualista; ignoran derechos colectivos que, en otras tradiciones culturales, forman parte de la identidad de los individuos.

La noción de ciudadanía cumple la función de establecer homogeneidad en la sociedad. Pero no realiza esa tarea mediante un diálogo concertado entre pueblos con puntos de vista distintos, sino mediante la imposición de los criterios de la nacionalidad o etnia dominante. En la concepción de ciudadanía se incluyen notas distintivas que forman parte de la nacionalidad dominante. El imaginario nacional no distingue entre los rasgos que definirían una ciudadanía común en un Estado multicultural y los característicos de una nacionalidad hegemónica. Piénsese en lo más obvio: la lengua oficial, las concepciones jurídicas, los procedimientos de elección y de gobierno, el contenido y orientación de la educación pública, los ritos y símbolos de convivencia nacional, los mitos y personajes históricos propuestos como ejemplo colectivo, se asocian a la imagen del buen ciudadano y todos ellos son los de la nacionalidad dominante dentro de un Estado.

Un ejemplo podría ilustrar la situación. Lo tomo de mi país, por conocerlo mejor, pero podría haber acudido a otras latitudes. Los pueblos indígenas de América no participaron en la constitución de la nueva república independiente. La unidad nacional fue impuesta por un grupo criollo mestizo occidentalizado. La nueva nación, con su nuevo concepto de ciudadanía, fue construida conforme a la concepción de ese grupo que se quería modernizador. Los derechos del ciudadano no incluyeron, en la práctica, el respeto a las formas de vida de todos los pueblos y, por ende, el derecho a las diferencias. Ciudadano era el que seguía la concepción predominante del Estado, obedecía al orden jurídico establecido por él, cumplía virtudes cívicas republicanas y participaba en los

\footnotetext{
${ }^{23}$ Teoria General del Estado, II, II, C, d.
} 
asuntos públicos según los procedimientos de la nueva cultura política. Durante los siglos XIX y XX, el ciudadano no se define solamente por sus derechos políticos, es también el miembro de una nueva nación mestiza, que comparte la visión de la sociedad propia de la cultura nacional y se adhiere a sus valores. Pero los pueblos indios mantenían su propia visión de la sociedad, seguían costumbres e instituciones sociales distintas, se regían por su orden jurídico no escrito y por sus procedimientos de participación política. El concepto de una ciudadanía común les hubiera ciertamente convenido, sólo si respetaba esas diferencias. De allí su lucha por una autonomía. Esta no proyecta la separación del Estado; por lo tanto no rechaza la ciudadanía nacional; pero implica la transformación del concepto de Estado nacional de manera de abarcar en él múltiples opciones de pueblos diferentes. Entonces el concepto de ciudadano tendría que adecuarse a una transformación semejante y no confundirse, por lo tanto, con el miembro de una nacionalidad dominante.

Lo cual nos conduce a la segunda alternativa que mencionamos para solucionar la aparente contradicción entre ciudadanía y autonomía; sería la "ciudadanía diferenciada" .

La ciudadanía diferenciada es una propuesta de Will Kymlicka. En México, un distinguido antropólogo, Guillermo de la Peña, ha propugnado por una solución semejante ${ }^{24}$. Parten de la comprobación de los derechos individuales comunes a todo ciudadano, para garantizar la libertad de elección real de los miembros de comunidades distintas a la hegemónica.

Propone una diferenciación de derechos por grupos sociales con ciertas características propias. En una sociedad "poliétnica" en la terminología de Kymlicka, los individuos pertenecientes de etnias distintas tendrian derechos diferenciados que les permitirían dar satisfacción a demandas específicas, sin constituir por ello asociaciones separadas de la sociedad global. En el caso de las que el mismo autor, llama Societal Cultures, es decir, culturas "cuyas prácticas e instituciones cubren un amplio rango de actividades, abarcando tanto la vida pública como la privada", ${ }^{25}$ tendrían derecho al "autogobierno" dentro de un Estado multicultural. Debería concedérseles, por lo tanto, una "ciudadanía diferenciada". Habría así una dóble ciudadanía: la común a todos los integrantes del Estado multicultural y la propia de una etnia o nacionalidad específica.

Esta propuesta intenta dar solución a las demandas legítimas de autonomía de los pueblos. Sin embargo, no deja de suscitar también serias objeciones.

La ciudadanía diferenciada, si la hubiere, no puede, en mi opinión, ser "é tnica" . En efecto, "é tnico" es un concepto cultural, se refiere a la pertenencia a una comunidad con formas de vida y proyectos comunes; "ciudadano", en

\footnotetext{
${ }^{24}$ W. Kymlicka, Multicultural Citicenship, Oxford, Clarendon Press, 1995. G. de la Peña, "La autonomía indígena en México: un debate inconcluso" en Signos, Guadalajara, núm. 3, mayo 1994, pp. 6-11.

${ }^{25}$ W. Kymlicka, op. cit., p. 75.
} 
cambio, es un concepto político; señala los derechos y obligaciones de una persona en cuanto está sujeta a un sistema de poder determinado. Atribuir etnicidad a la ciudadanía es caer en el mismo equívoco que yo reprochaba a la concepción opuesta: incluir en las notas que definen al ciudadano caracteres que corresponden a una concepción de la sociedad propia de una cultura particular. Ciudadanía y etnicidad (o nacionalidad) son compatibles sólo si no se incluyen en aquélla caracteres que corresponden a ésta; si se restringe la definición de ciudadanía, por lo tanto, a las notas que deba tener cualquier persona por ser sujeto político de un Estado, con independencia de la etnia o nacionalidad a la que pertenezca. Los derechos del ciudadano deberían así separarse de los que adquiera una persona o un grupo por pertenecer a una comunidad autónoma.

Por otra parte, consignar en la legislación ciudadanías diferenciadas por características culturales o étnicas de sus miembros sería sumamente dificil en la práctica. ¿Mediante qué criterios se adscribiría un individuo a una variante ciudadana? ¿Sería una auto-adscripción? En ese caso, se prestaría a ser utilizada por conveniencias particulares. ¿Con base a un criterio cultural, como la lengua o ciertas prácticas sociales? Pero en una región donde las etnias se encuentren mezcladas, sin territorios delimitados con precisión, es casi imposible aplicar criterios semejantes.

Lo anterior nos conduce a una tercera y última propuesta. Frente a la ciudadanía única y la ciudadanía étnica, podríamos considerar una variante de ciudadanía diferenciada; llamémosla "ciudadanía restringida".

Dijimos que el criterio para otorgar ciudadanía a un sujeto es su facultad de participación política. Por lo tanto, si el concepto de ciudadanía no ha de excluir a nadie, tendría que ser acordada a toda persona moral con capacidad de decisión en asuntos públicos. Debería otorgarse por igual a todos los diferentes en situación económica, en nacionalidad, en cultura o en género, con tal de que fueran capaces de participar activamente en los asuntos del Estado. Solo se podría negar la ciudadanía a quienes carecieran de capacidad de decidir por sí mismos, sobre su propia vida y la vida colectiva, de manera que otros tuvieran la responsabilidad de decidir por ellos. En esa situación están los menores de edad y los incapacitados mentales. Todos los demás serían sujetos políticos con los mismos derechos, en tanto miembros iguales del mismo Estado.

En consecuencia, en una comunidad política no excluyente, todo sujeto de derechos humanos, con capacidad de participación política, sería también ciudadano. Se eliminaría, por lo tanto, la diferencia entre comunidad de sujetos de derechos humanos y comunidad de sujetos de derechos ciudadanos.

: La única diferencia consistiría en que los derechos humanos se fundan en el reconocimiento por el Estado de valores inherentes a toda persona, por ser tal, y los derechos del ciudadano son otorgados a todo aquel que, además de los valores de la persona, tiene la capacidad de participar por sí mismo en la esfera política.

La ciudadanía no excluyente tendría las siguientes consecuencias: 
1. No podría aceptar ninguna separación entre ciudadanos "activos" y "pasivos" o ciudadanos con mayores derechos que otros. Implicaría, por lo tanto, que toda persona adulta y en uso de sus facultades tendría los mismos derechos a participar en los asuntos de Estado. La idea de una ciudadanía no excluyente es un aspecto, por lo tanto, de una democracia participativa radical.

2. Implicaría la separación tajante del concepto de ciudadanía, referente a la relación de una persona con el Estado, y los conceptos de nacionalidad o etnia, relativos a la pertenencia de una persona a una comunidad de cultura. La ciudadanía establecería la igual responsabilidad de los integrantes de distintos pueblos, con culturas diferenciadas, en participar en un sistema de poder común a todos.

3. Por lo tanto, los derechos y obligaciones de los ciudadanos quedarían restringidos a la relación política de todo sujeto con el Estado. Incluirian sus modos de participación política con las variantes diferenciales que decidieran los pueblos autónomos que constituyen el Estado.

En consecuencia, en un Estado multicultural la ciudadanía común no podría incluir ningún derecho ni obligación que no pudiera ser reconocido por alguno de los pueblos que lo constituyen. Por ejemplo, en los países americanos de raíces indígenas no podría comprender la inviolabilidad de toda propiedad individual o los procedimientos electorales de una democracia sustentada en partidos. En efecto, muchos pueblos indígenas consideran la propiedad colectiva indispensable para el mantenimiento de la comunidad y practican procedimientos de democracia directa ajena a la manipulación partidaria. Sin embargo, todos ellos pueden cumplir con el derecho de todo ciudadano a poseer propiedades y a participar en las decisiones públicas. Por último, es obvio que ningún valor específico de una cultura o nacionalidad, como los que conlleva una religión, una lengua o una tradición histórica, debería estar ligado al concepto común de ciudadanía.

4. Los derechos ciudadanos deberían distinguirse de los que corresponden a un sujeto por pertenecer a un pueblo. Estos últimos se basan en el derecho de autodeterminación de todo pueblo: deben ser reconocidos por el Estado multicultural. Los derechos ciudadanos, en cambio, son el resultado del acuerdo entre los diferentes elementos que convienen en unirse en un Estado respetando los derechos humanos; son otorgados por éste al constituirse. En consecuencia, los derechos de los integrantes de un pueblo deben ser determinados por ese pueblo y quedar consignados en los instrumentos que definan su autonomía frente al Estado. Los derechos comunes del ciudadano, en cambio, serían producto del acuerdo, tácito o expreso, de los distintos pueblos.

5. La ciudadania restringida, basada en el acuerdo de todos, se distingue, por lo tanto, de los derechos y obligaciones particulares instaurados por los distintos pueblos autónomos. El reconocimiento de autonomías es pues compatible con la unidad de una ciudadanía común. Una ciudadanía restringida constituiría un marco para la unión de culturas y etnias diferencias. La unión 
se llevaría al cabo al nivel del Estado, no de la nación o de la etnia. Tendría por fin la cooperación de los distintos pueblos en un propósito solidario. Establecería así normas comunes, en el respeto a todas las variantes culturales y en la colaboración entre ellas. El concepto de una ciudadanía común forma parte del proyecto de equidad para todas las diferencias, marcando para todas ellas el objetivo de una cooperación recíproca.

\section{IV}

Pasemos ahora a la segunda forma de exclusión propiciada por la concepción de ciudadanía ligada al Estado-nación: la de los extranjeros.

La mayor parte de los inmigrantes y residentes extranjeros en los países desarrollados, provenientes en su mayoría de sociedades con problemas de empleo, contribuyen a su prosperidad económica y a la riqueza de su cultura, están sometidos a los cargos de cualquier ciudadano y, sin embargo, carecen de los mismos derechos. A ellos habría que añadir los apátridas, individuos que no poseen un pasaporte nacional y son rechazados por muchos países. Ambas categorías carecen de acceso a vías de participación política para defender sus intereses, están amenazados de expulsión y no son considerados iguales a los demás en una distribución equitativa de bienes y servicios. En realidad, pese a ser sujetos morales, con plenos derechos humanos, son marginados por la sociedad en la que viven y trabajan. Como indica Javier de Lucas: el trabajador extranjero residente "se ve privado del reconocimiento como auténtico sujeto de derecho, reservado en exclusiva a la ciudadanía". ${ }^{26}$ Esta injusticia es inherente al estatuto de "ciudadanía" ligado al concepto de Estado- nación homogéneo en el interior y soberano frente al exterior. La única justificación que podría alegar sería pues el interés de ese Estado- nación. En este sentido, solo podría aducir tres razones para no conceder plenos derechos de ciudadanía a los inmigrantes, residentes extranjeros y apátridas:

1) Las necesidades de defensa interior del Estado soberano: obligación de cumplir el servicio militar para los nacionales, vigilancia de los no nacionales en caso de conflicto exterior.

2) Las obligaciones del Estado- nación de otorgar protección diplomática a sus ciudadanos cuando residen en el extranjero; lo cual implica que cada Estado acepte competencias exclusivas sobre sus propios ciudadanos nacionales.

3) La conveniencia de regular el mercado laboral y protegerlo del daño que podría causar el exceso de oferta de trabajo por parte de los extranjeros. : Aparte de esas tres razones, nacidas de la división mundial en Estados nacionales soberanos, no se ve otra justificación para excluir a los extranjeros de plenos derechos de ciudadanía. Las tres razones dejarían de ser válidas con la desaparición de los Estados nacionales. Sólo entonces, el fin de las

\footnotetext{
${ }^{26}$ J. de Lucas, El desafio de las fronteras, Madrid, Temas de hoy, 1994, p. 133.
} 
fronteras, de los conflictos armados y de la competencia económica entre las naciones vería también el término de las exclusiones causadas por las ciudadanías nacionales.

Pero esa situación es aún lejana. Por mucho tiempo pertenecerá al reino de la utopía. Sólo puede fungir como una idea regulativa para ir reduciendo paulatinamente las diferencias entre ciudadanos y sujetos morales excluidos de la ciudadanía.

En el interior de la Nación- Estado cabría una progresiva ampliación de los derechos de los extranjeros residentes para acercarlos a los nacionales. Me parece razonable la posición expresada por Javier de Lucas: mientras subsista el Estado- nación no podría admitirse ninguna violación de los derechos humanos de los extranjeros, pero sí cabría establecer restricciones ligadas a las necesidades propias de cada Estado- nación. ${ }^{27}$ Sin embargo esas restricciones solo podrian estar justificados en la aplicación a las necesidades específicas de una nación, de los principios generales de justicia - de los que hablé en la conferencia pasada. A mi juicio, las restricciones deberian seguir los siguientes principios:

1) En ningún caso podría negarse a los extranjeros, cualquiera que sea su estatuto legal, los derechos inherentes a todo sujeto moral, que comprenden el ejercicio de las libertades mínimas que mencioné en la conferencia pasada.

2) Las restricciones de los otros derechos de que gozan los ciudadanos nacionales deberian regirse por un principio que podríamos establecer en analogia con el Segundo Principio de Rawls. Serían admisibles solamente en la medida en que redundaran en beneficio general de todos los miembros de la sociedad. En consecuencia, su aplicación a nuestro tema implicaría:

a) Los extranjeros y apátridas residentes que ya forman parte de la sociedad nacional deberían tener los mismos derechos y obligaciones que los ciudadanos, sin ningún requisito adicional, con las únicas restricciones que conciernen a la seguridad nacional.

b) Las restricciones de ingreso al país y de derechos laborales de los inmigrantes extranjeros en busca de trabajo se jusțificarían solamente en la medida estricta en que se demostrara que su abolición causaría un daño grave a la economía nacional

c) Esas restricciones deberían estar reguladas por acuerdos entre los países receptores y los exportadores de trabajadores, y darian lugar a convenios internacionales.

Esta es sólo una tentativa de propuesta de principios generales. Su aplicación concreta variaría según las circunstancias.

Llegamos así al final de estas conferencias. Gracias a la generosa invitación del Instituto de Filosofía y a la hospitalidad de la Residencia de Estudiantes, he tenido la oportunidad de esbozar lo que sería una teoría de la justicia

\footnotetext{
${ }^{27}$ J. de Lucas, op. cit., p. 148.
} 
que partiera de las experiencias históricas de exclusiones vividas. La percepción personal de las injusticias es quizás más obvia en los países alejados del desarrollo económico de los europeos o norteamericanos y de su orden democrático. La marginacion de los diferentes es vivida con mayor intensidad por los pueblos que, en algún momento de su historia, sufrieron la colonización; las desigualdades sociales, por los miserables de los países pobres; las exclusiones de la ciudadanía, por inmigrantes en busca de un modo mejor de vida. Pero todas esas formas de exclusión, al lado de otras distintas, no están ausentes tampoco de los países más desarrollados. Por ello pueden servir de punto de partida para una concepción general de la justicia.

Las exclusiones en que se basa la injusticia son múltiples. Cada una se refiere a un aspecto de la vida en sociedad y no incluye necesariamente otros rechazos. La exclusión de los diferentes por su raza o por sus creencias religiosas no es la misma que la de quienes tienen distintas preferencias sexuales; las discriminaciones por pertenecer a una etnia o por ser del género femenino no tienen nada en común; el rechazo del pobre o el inculto, por serlo, o del inmigrante por extranjero no son el mismo rechazo. Por eso las manifestaciones de la injusticia son variadas y los sujetos que las padecen pertenecen a categorías no equiparables.

Esto significa que no hay un solo sujeto colectivo portador de la injusticia, ni una sola clase destinada a eliminarla, como llegó a pensar un catecismo marxista. Cualquier teoria de la revolución que intentara avanzar hacia una sociedad más justa tendría que tomar en cuenta esa diversidad de sujetos históricos.

La sociedad más justa se presentará siempre como una idea regulativa por alcanzar, guía para las luchas más diversas de grupos sociales con exigencias diferentes. Pero esa idea sería en todas ellas, semejante: alcanzar una comunidad en que sus miembros fueran solidarios en el respeto a todas las diferencias. 